\section{INVITED SPEAKER ABSTRACTS}

\section{IS-01}

\section{CANCER: ION CHANNELS - MULTIPLE POTENTIAL FOR THE EFFECTIVE MANAGAMENT OF A COMPLEX DISEASE.}

\section{Mustafa B A Djamgoz ${ }^{1,2}$}

${ }^{1}$ Department of Life Sciences, Neuroscience Solutions to Cancer Research Group, Sir Alexander Fleming Building, Imperial College London, South Kensington Campus, London SW7 2AZ, U.K.

${ }^{2}$ Cyprus International University, Biotechnology Research Centre, Haspolat, North Cyprus.

Cancer, now the biggest killer of man in affluent countries, is an extremely complex disease! Not surprisingly, therefore, many problems remain in its clinical management, in spite of the millions of dollars spent on basic and applied research. The problems include uncertainties in diagnosis (i.e. lack of functional biomarkers), limited effectiveness and highly undesirable side effects of even targeted therapies, including immunotherapy, and cost! Intrinsic and extrinsic factors contribute to these problems. Intrinsically, cancer cells may express several hundred genes that are different from normal and behave extremely dynamically, changing constantly in space and time as well as in response to treatment. Extrinsically, there are the politics and the economics of cancer! In most cases of cancer, it is "metastasis" that is the main cause of death. Coming through the 'decade of the brain' in the 1990s, and armed with more than 25 years of neuroscience research experience, we asked, for the first time, whether cancer cells of different metastatic ability (i.e. strong/malignant versus weak/benign) differed in their voltage-gated ion channel expression? We focused on voltagegated ion channels because of the profound impact of the membrane potential (equivalent to ca. 10 million Volts per meter) on individual proteins and cellular behaviours as a whole. This unique approach has led to a novel vision ("Celex Hypothesis") of metastasis in which cancer cells' electrical excitability and the resulting hyperactivity drive (perhaps even initiate) metastasis. At the core of this excitability phenomenon is the de novo expression of voltage-gated sodium channels (VGSCs), normally associated with the so-called 'excitable' cells of the body such as nerves and muscles. These VGSCs have several properties that make them an ideal anti-cancer target, summarised as follows:

\begin{tabular}{|l|l|}
\hline VGSC property & Clinical consequence(s) \\
\hline $\begin{array}{l}\text { mRNA expression several orders } \\
\text { of magnitude higher in strongly } \\
\text { vs. weakly metastatic cancers }\end{array}$ & $\begin{array}{l}\text { Potential functional diagnostic molecular } \\
\text { biomarker }\end{array}$ \\
\hline $\begin{array}{l}\text { Expression is early and upstream } \\
\text { of the genes driving invasiveness }\end{array}$ & $\begin{array}{l}\text { Potential functional 'early' marker, ideal } \\
\text { for diagnostics }\end{array}$ \\
\hline $\begin{array}{l}\text { Upregulation maintained at pro- } \\
\text { tein and functional (signalling) } \\
\text { levels }\end{array}$ & $\begin{array}{l}\text { Diagnostics can be extended to conven- } \\
\text { tional immunohistochemistry and even } \\
\text { clinical MRI }\end{array}$ \\
\hline $\begin{array}{l}\text { Gene / protein expressed in neona- } \\
\text { tal splice form in several carcino- } \\
\text { mas; targetable by antibody }\end{array}$ & $\begin{array}{l}\text { Antibody can be used as a drug (i) to } \\
\text { block channel activity / metastasis and/or } \\
\text { (ii) kill tumour cells (in ADC mode) }\end{array}$ \\
\hline $\begin{array}{l}\text { Activity-dependent up-regulation } \\
\text { (positive feedback) }\end{array}$ & $\begin{array}{l}\text { VGSC blockage would suppress also ex- } \\
\text { pression of the channel, thereby provid- } \\
\text { ing long-term benefit }\end{array}$ \\
\hline $\begin{array}{l}\text { Channel activity promotes inva- } \\
\text { siveness in vitro as well as metas- } \\
\text { tasis per se in vivo }\end{array}$ & $\begin{array}{l}\text { Therapeutic potential - possible 'repur- } \\
\text { posing' of existing VGSC drugs (as well } \\
\text { as novel antibody) }\end{array}$ \\
\hline $\begin{array}{l}\text { Under hypoxic conditions, as in } \\
\text { growing tumours, VGSCs develop } \\
\text { a persistent current (INaP) }\end{array}$ & $\begin{array}{l}\text { Invasiveness can be suppressed by inhib- } \\
\text { iting INaP alone, using drugs like ranola- } \\
\text { zine }\end{array}$ \\
\hline $\begin{array}{l}\text { Functional expression under the } \\
\text { control of steroid hormones and } \\
\text { growth factors }\end{array}$ & $\begin{array}{l}\text { VGSC is integral to 'mainstream' cancer } \\
\text { mechanisms; therapeutic potential ex- } \\
\text { tends to 'combination' treatments }\end{array}$ \\
\hline
\end{tabular}

IS-02

THE USE OF SYSTEMS BIOLOGY IN TREATMENT OF LIVER
CANCER

Adil Mardinoğlu

KTH-Royal Institute of Technology King's College London, U.K.

To develop novel strategies for prevention and treatment as well as to gain detailed insights about the underlying molecular mechanisms of liver diseases, it is vital to study the biological functions of liver and its interactions with other tissues and gut microbiota. Biological networks can provide a scaffold for studying biological pathways operating in the liver in connection with disease development in a systematic manner. In my presentation, I will present our recent work where biological networks have been employed to identify the reprogramming in liver physiology in response to liver cancer. I will further discuss how this mechanistic modelling approach can contribute to the discovery of biomarkers and identification of drug targets which may lead to design of targeted and effective treatment strategies.

Key points of my presentation

- Omics technologies are used in detailed characterization of human liver tissue in health and disease states.

- Biological network models are functional tools for exploring and integration of multiomics data.

- Systems biology uses a holistic and integrative approach for comprehensive analysis of the biological functions in healthy and diseased states

- Systems Biology approaches have been successfully employed in hepatology to identify biomarkers and drug targets.

- These integrative tools can be used for simulation of liver tissue functions and its crosstalk with other tissues for prediction of therapeutic and side effects Keywords: systems biology, biological networks, patient stratification

\section{IS-03}

\section{DIETARY CONTROL OF STEM CELLS IN PHYSIOLOGY AND} DISEASE

\section{Ömer Hidır Yılmaz}

MIT-Koch Institute For Integrative Cancer Research, USA

My laboratory studies how adult stem cells and their microenvironment adapt to various diets in the context of tissue regeneration, aging, and cancer initiation. However, the mechanisms through which diet perturbs stem and progenitor cell biology and leads to diseases, such as cancers are poorly understood. Towards this end, we are studying how diverse dietary interventions such as calorie restriction (CR), fasting and high fat diet (HFD)-induced obesity impact intestinal stem cell (ISC) and progenitor function in the mammalian intestine. Since ISCs, like all adult stem cells, possess the ability to self-renew (i.e. generate daughter stem cells) and the capacity for multipotent differentiation (i.e. generate lineagecommitted progenitors and ultimately all mature tissue-specific cell types), they likely play an important role in remodeling the intestine in response to diet-induced physiologies. A majority of ISCs express the leucine-rich repeatcontaining $\mathrm{G}$ protein-coupled receptor $5(\operatorname{Lgr} 5)$ and reside at the bottom intestinal crypts nestled between Paneth cells in the small intestine and deep secretory cells in the colon; both Paneth cells and deep secretory cells constitute a significant component of the stem cell cellular neighborhood or "niche". Such niche cells elaborate myriad growth factors and cues necessary for the maintenance of Lgr5+ ISCs. This intercalated positioning of Lgr5+ ISCs and their niche cells make the intestine an elegant system for deciphering the autonomous versus nonautonomous (or niche-mediated) effects of different diets and the gut microbiome on stem cell self-renewal and differentiation and how changes in ISCs contribute to cancer formation and growth. In addition, my lab has developed numerous tools and techniques that enable Crispr/Cas9 genetically defined intestinal cancer organoids that can be endoscopically transplanted into the colons of recipient mice. Furthermore, we have devised endoscopic methods for mucosal directed Crispr/Cas9 genome editing to establish intestinal tumors. The development of such tools enables us to dissect how tumor initiation, growth, aging, metastasis, immunosurveillance and drug resistance are influenced by diverse dietary states and the gut microbiome, which will be the focus of my presentation. 


\section{IS-04 \\ TRPM8 CHANNEL PUTS THE CHILL ON PROSTATE CANCER CELL MIGRATION}

\section{Dimitra Gkika}

Laboratoire de Physiologie cellulaire, Inserm U1003

Laboratory of Excellence, Ion Channels Science and Therapeutics

Université de Lille, 59655 Villeneuve d'Ascq Cedex, France

Prostate cancer (PCa) is one of the most frequently diagnosed cancers in developed countries. Several studies suggest that variations in calcium homeostasis are involved in carcinogenesis. Interestingly, TRPM8 calcium permeable channel expression is differentially regulated during prostate carcinogenesis, thereby suggesting a potential functional role for this channel in those cell processes, which are important for $\mathrm{PCa}$ evolution. Indeed, several studies have shown that TRPM8 plays a key role in processes such as the proliferation, viability and cell migration of PCa cells. Where cell migration is concerned, TRPM8 seems to have a protective anti-invasive effect and could be a particularly promising therapeutic target.

\section{IS-05}

APPLICATION OF IN SILICO APPROACHES FOR THE DEVELOPMENT OF NOVEL ANTI-CANCER THERAPEUTICS WITH DESIRED PHARMACOKINETIC PROFILES

\section{Serdar Durdag 1}

Computational Biology and Molecular Simulations Laboratory, Department of Biophysics, School of Medicine, Bahcesehir University, İstanbul, Turkey

Computational chemistry provides a range of simulation tools for description of protein-ligand and protein-protein binding, statistical methods for analysis of the binding data helps to predict the new therapeutics for specific diseases with desired pharmacokinetic profiles. Molecular modeling tools enable construction of novel ligands. In recent years, a growing number of defined X-ray as well as NMR and cryo-EM structures and access to these structures from the protein database (PDB, protein data bank) have enabled these data to be used as template targets in molecular modeling studies. In this talk, examples of target-based and ligand-based virtual screening of small molecule libraries for different targets will be highlighted.

\section{IS-06}

\section{FUNCTIONAL IMPLICATIONS OF ALTERED GENE EXPRESSION PATTERN OF STORE-OPERATED CALCIUM CHANNELS IN LIVER CANCER}

\section{Metiner Tosun}

Izmir University of Economics, School of Medicine, Dept. of Pharmacology 35330 Izmir, Turkey

Besides physiological processes, spatio-temporal changes in intracellular $\mathrm{Ca}^{2+}$ signaling play a crucial role in carcinogenesis. Store-operated $\mathrm{Ca}^{2+}$ Entry (SOCE) is a major $\mathrm{Ca}^{2+}$ entry pathway for non-excitable cells including hepatocytes. The main reason of the recurrence of cancer after treatments appears to be resulted from chemoresistant tumor initiating cell (TIC) subpopulation found in tumor heterogeneity. Therefore, the purpose of this study was to delineate the role of SOCE in TICs in Huh-7 HCC cell line expressing certain specific cell surface antigens, EpCAM and CD133. For this purpose, we investigated the $\mathrm{Ca}^{2+}$ homeostasis mechanism and also performed target validation on functional SOCE in these cell subpopulations $\left(\mathrm{EpCAM}^{+} \mathrm{CD} 133^{+}\right)$. We initially separated these cells from parental cells via a cell sorter (Fluorescent Activated Cell Sorter, FACSAria III, BD) employing fluorophore-conjugated specific antibodies targeting their cell surface antigens of interest, then, enhanced the expressions of two functionally important SOCE components, an ER integral membrane protein of endoplasmic reticulum (ER) that senses intra luminal $\mathrm{Ca}^{2+}$ content, stromal interaction molecule (STIM1) and a membrane $\mathrm{Ca}^{2+}$ influx protein (Orai1), in TICs. Later, we investigated the roles of these proteins in real-time changes of intracellular $\mathrm{Ca}^{2+}$ levels due to $\mathrm{ER} \mathrm{Ca}^{2+}$ release and SOCE besides monitoring cell proliferation rate and multidrug resistance (MDR1) gene expression. Based on our data, ER $\mathrm{Ca}^{2+}$ release and SOCE were higher in TICs compared to that in EpCAM-CD133cells. Slow proliferation rates of TICs comparable to that of the parental cells might due to $\mathrm{Ca}^{2+}$ buffering that holds these cells in an undifferentiated state. Enhancement of STIM1 and Orail expressions in TICs led to a more effective
SOCE in $\mathrm{EpCAM}^{+} \mathrm{CD} 133^{+}$cells. This observation may confirm the stoichiometric relationship between STIM1 and Orail expressions suggested earlier. Upregulation of MDR1 gene in STIM1- and Orail-overexpressing TICs also suggests a causal relationship between SOCE elevation and MDR development. Based on our functional and ongoing genomic (transcriptome \& miRNome) analyses, STIM1 and Orail appear to be important for $\mathrm{ER} \mathrm{Ca}^{2+}$ buffering capacity and SOCE entry operation mechanism, respectively, which are crucial upstream events for cell survival. Targeting the TICs for SOCE components STIM1-Orai1 and their related signaling pathways as well as manipulating related miRNAs may support development of specific anticancer strategies. (This work was financially supported by the Scientific and Technological Research Council of Turkey, TUBITAK 113 S399 to M.T.).

Keywords: Huh-7; HCC; SOCE; STIM1; Orai1

\section{IS-07 \\ TRPM2 AND TRPV1 CHANNELS: POTENTIAL DRUG TARGETS FOR TREATING CHEMOTHERAPEUTIC DRUG-INDUCED NEUROPATHIC PAIN*}

\section{Mustafa Nazıroğlu ${ }^{1,2,3}$}

${ }^{1}$ Neuroscience Research Center, Suleyman Demirel University, Isparta, Turkey ${ }^{2}$ Department of Biophysics, Faculty of Medicine, Süleyman Demirel University, Isparta, Turkey

${ }^{3}$ BSN Health, Analyses, Innovation, Consultancy, Organization, Agriculture, Industry and Trade Limited Company, Göller Bölgesi Teknokenti, Isparta, Turkey

OBJECTIVES: Cancer is an important public problem, although incidence of cancer was reduced by the discovering several new chemotherapeutic drugs. Pain is very common adverse effects of the chemotherapeutic agents, because $75-90 \%$ of the cancer patients are suffering from the neuropathic pain (1). Abnormal $\mathrm{Ca}^{2+}$ channel physiology and expression have been implicated in a number of pain states in cancer treatment with chemotherapeutic drugs. The TRPM2 channel is activated by poly (ADP-ribose) polymerase (PARP) pathways through the production of ADP-ribose and oxidative stress. The TRPV1 is activated by hot chili pepper component (capsaicin) and reactive oxygen species (ROS) (2). The expression levels of TRPM2 and TRPV1 are high in the DRG neuron (2). ROS acts a central role in chemotherapeutic drug-induced dorsal root ganglion (DRG) death and peripheral pain (3).

RESULTS: In addition to chemotherapeutic drugs-induced peripheral pain induction, several studies suggested that that mitochondrial oxidative stress is one of main reasons that cause peripheral neuropathy and neurotoxicity; taxanesinduced mitochondrial damage and accumulation of excessive $\mathrm{Ca}^{2+}$ increases mitochondrial oxidative injury, resulting in apoptosis in the neurons. Selenium is strong antioxidant trace element in cisplatin-induced oxidative stress. Recently we observed modulator role of selenium on apoptosis, oxidative stress and calcium entry through TRPM2 and TRPV1 channels in DRG neuron of fibromyalgiainduced rats (3). In this presentation, I will summarize our and other recent experimental research findings on how these chemotherapeutic drug-induced oxidative stresses, TRPM2 and TRPV1 activations are regulated in peripheral pain by antioxidants such as selenium.

CONCLUSIONS: Present data suggested that the mechanisms of chemotherapeutic drugs-induced neuropathic pain and oxidative neurotoxicity may be mediated via the TRPM2 and TRPV1 channels in the DRG neurons. However, the pain, oxidant, and apoptotic effects of chemotherapeutic drugs were reversed through the inhibition of TRPM2 TRPV1 in the DRG by the selenium treatment.

Keywords: Chemotherapeutic drugs; Oxidative stress; Neuropathic Pain; Selenium; TRPV1 Channel.

*The project was supported by Small and Medium Industry Development Organization (KOSGEB)-Isparta, Turkey. Project Number (2017/AGI.04)

\section{REFERENCES}

1. Mohsenzadegan M, Seif F, Farajollahi MM, Khoshmirsafa M. (2018) AntiOxidants as chemopreventive agents in prostate cancer: A gap between preclinical and clinical studies. Recent Pat Anticancer Drug Discov. 13(2), 224-239.

2. Nazıroğlu M and Braidy N (2017) Thermo-sensitive TRP channels: Novel targets for treating chemotherapy-induced peripheral pain. Front. Physiol. 8:1040.

3. Yüksel E, Nazıroğlu M, Şahin M, Çiğ B (2017). Involvement of TRPM2 and TRPV1 channels on hyperalgesia, apoptosis and oxidative stress in rat fibromyalgia model: Protective role of selenium. Sci Rep. 7:17543. 


\section{IS-08}

\section{GLUCOSE METABOLISM IN CANCER}

\section{A. Lale Doğan}

Hacettepe University Cancer Institute, Department of Basic Oncology, Ankara, Turkey

Normal differentiated cells rely primarly on mitochondrial oxidative phosphorylation to generate the energy needed for cellular anabolic processes. On the other hand, cancer cells are distinguished from normal cells by accelerated aerobic glycolysis, a phenomen termed "the Warburg effect". Glucose metabolism involves not only glycolysis but also other pathways that use glucose. These pathways are, pentose phospahate pathway which generates ribonucleotides, hexosamine pathway which is involved in generation of metabolites for glycosylation, glycogenesis for the storage of glucose and serine biosynthesis which participates in amino acid generation. In cancer cell, the enzymes and transporters of which expression or activity is increased are known as, GLUT1 (glucose transporter protein), HK2 (hexokinase2), PFKFB3(6phosphofructo2-kinase/fructose-2,6-bisfosfatase), ALDO A(aldolase), PKM2 (pyruvate kinase), LDHA(lactate dehydrogenase) ve MCT1-4 (monocarboxylate transporter protein). Several oncoproteins either increase the expression or induce the activity of enzymes and transporters which participate in accelerated glucose metabolism in cancer cells. The high rate of glucose metabolism serves for fulfilling anabolic demands of the cancer cell.

Keywords: Warburg effect, glycolysis, cancer, metabolism

\section{IS-09}

CONSIDERING CANCER AS A METABOLIC DISEASE: BEYOND WARBURG EFFECT

\section{Mustafa Guzel ${ }^{1,2}$}

I'stanbul Medipol University, Regenerative and Restorative Medicine Research Center (REMER), Kavacik Campus, Kavacik-Beykoz, İstanbul, Turkey

${ }^{2}$ Istanbul Medipol University, International School of Medicine, Department of Medical Pharmacology,Kavacik Campus, Kavacik-Beykoz, İstanbul, Turkey

Cancer now surpasses heart disease as leading cause of death in many countries of the world. Clinical validations prove that protein kinases are an attractive class of therapeutic drug targets for cancer as demonstrated with the recent approval of six protein kinase inhibitors. The Warburg effect describes the particular reliance of cancer cells on glycolysis for energy. Increased glycolysis and acid resistance have been postulated to be an essential part of carcinogenesis, conferring a significant growth advantage as well as promoting typical tumor progression. Warburg hypothesized that the energy consumption of cancer cells is different than the normal cells. When compared to normal conditions, cancer cells do not undergo tricarboxylic acid (TCA) cycle therefore resulting in more lactate in the cells. Glycolysis pathway is a way of cancer cells to provide energy. Targeting accelerated glycolysis in cancer cells is a new promising modality for treatment of cancer. Inhibition of glycolysis can be done without significant side effects, and such treatment will be additive to most known cancer therapies. The first step in glycolysis is the phosphorylation of glucose to glucose-6-phosphate. This reaction is catalyzed by the hexokinase-II enzyme (HK-II) which is known to be overexpressed in tumor cells. The feeding of cancer cells can be prevented by inhibiting the hexokinase-II enzyme in the first step of aerobic glycolysis. In literature, Methyl Jasmonate (MJ) is known as a Hexokinase-II inhibitor since it disposes VDAC and HK-II interaction on mitochondrial membrane. In our study, we aimed to increase the activity by synthesizing the novel MJ analogues with appropriate modifications. Recent studies show that Methyl Jasmonate reveals promising results for treatment of cancer as a HK-2 inhibitor. Cis-jasmone, Jasmonic acid and Methyl jasmonate are cyclopentanones that are fatty acid derivatives. Jasmonates are plant stress hormones which exhibit abnormal anticancer activity [1]. Jasmonates induced suppression of cell proliferation and death in a variety of cancer cell lines and cytotoxicity to cervical cancer cells with almost no effect on normal primary human keratinocytes [2]. As a result of our research, although methyl jasmonate is long-known natural product, it has not well-studied as an anti cancer agent.

Based on the three different cancer cell lines we investigated, our novel MJ analogues proved to be more potent than the original molecule. Thus this research may provide more efficacious/novel HK-II inhibitors and may shed light to develop new anti-cancer agents. In our research laboratory, we designed and synthesized handfull of novel methyl jasmonate analogs. We will highlight the biological activity of those novel analogs as anti-cancer agents.
This project (215S890) is funded by TUBITAK. We kindly appreciate for their support.

Keywords: Cancer Metabolism, Methyl Jasmonate, Novel drug design and development, Anti-cancer Agents
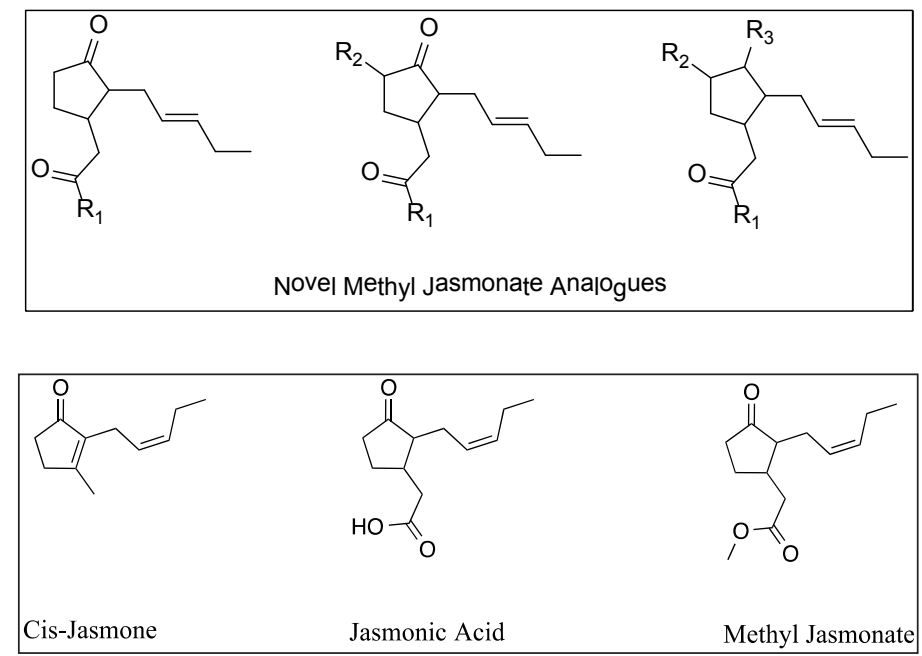

Figure 1: Cis-Jasmone, Jasmonic Acid, Methyl Jasmonate and Novel Methyl Jasmonate Analogs

\section{REFERENCES}

1. Rotem, R. et. al. 2005. "Jasmonates: Novel anticancer agents acting directly and selectively on human cancer cell mitochondria", Cancer Research, 65(5), 1984-1993

2. Kniazhanski, T. et al. 2008. "Methyl jasmonate induces cell death with mixed characteristics of apoptosis and necrosis in cervical cancer cells", Cancer Letters, 271, 34-46.

\section{IS-10}

\section{GLUT1 IN CANCER METABOLISM}

\section{Emine Acar}

İzmir Katip Çelebi University, İzmir, Turkey

Positron emission tomography (PET) with fluorine-18 fluoro deoxy-glucose (FDG) is recognized as an accurate, non-invasive cancer imaging modality (diagnosis, staging, restaging, and treatment response). With conventional imaging modalities, size, shape, invasion used to distinguish between benign and malignant disease; conversely, FDG PET is based on identification of fundamental aspects of tumor metabolism. The method is based on identifying the increased glycolytic activity in malignant cells (Warburg effect), in which glucose is preferentially concentrated due to an increase in membrane glucose transporters. FDG is transported into tumor cells, similarly to glucose, by means of GLUT transporter proteins known as GLUT transporters and subsequently phosphorylated by hexokinase to FDG 6-phosphate. FDG 6-phosphate is not efficiently metabolized further and therefore accumulates within the cell. This process of "metabolic trapping" of FDG in the cell constitutes the basis for imaging the in vivo distribution of the tracer with FDG PET. It is possible to image the entire body in a single session, increasing the opportunity for finding unsuspected disease sites. FDG avidity is high in many tumors. However, welldifferentiated tumors or tumors with low doubling time may not be FDG avid. On the other hand, benign tumors with high cleavage rates may show FDG accumulation. Therefore, experience in PET interpretation, knowing the patient and the characteristics of the disease is very important.

Keywords: glucose, cancer metabolism, GLUT, FDG, PET 
IS-11

\section{OLIVE, CANCER AND METASTASIS}

Hatice G. Aktas

Harran University, Faculty of Arts and Science, Biology Department, Sanliurfa, Turkey

The symbol of peace, olive tree, a perennial plant, is grown for nutritious fruits and oil obtained from these fruits. Different parts of the plant and its products are used for medical and cosmetic purposes as well as nutrition. From the past to the present, the olive has been one of the indispensable elements of traditional medicine in the Mediterranean countries, where the plant grows naturally. Olive oil is widely used both in kitchens as an essential nutrient and in cosmetics owing to be skin friendly. Olive leaves containing various polyphenolic compounds have been reported to protect the body against many diseases such as diabetes, cardiovascular disorders, high cholesterol, and urinary system disorders. Oleuropein, the phenolic component found at the highest amount in the leaves and fruits of the olive tree, has been shown to cause the most of these effects.

Additionally, some studies are on the cytotoxic effects and anticancer activity of the compound. Various researchers have revealed that oleuropein may cause cytotoxic, antiproliferative or apoptotic effects in cancer cell lines including prostate (LNCaP, DU-145, PC-3), breast (MCF-7, MDA-MB-231, T-47D), liver (HEP3B), lung (A549), and colorectal (LoVo). Further, they have demonstrated that the compound may inhibit cell migration by suppressing matrix metalloproteinase expressions or disrupting actin filaments. Oleuropein has also been shown to affect $\mathrm{Ca}^{2+}$ channels and $\mathrm{Ca}^{2+}$ homeostasis. In a study, it has been found that in human hepatoma cells, oleuropein promotes cytoplasmic levels of $\mathrm{Ca}^{2+}$ through store-operated $\mathrm{Ca}^{2+}$ channels and the release of $\mathrm{Ca}^{2+}$ from ER to cytoplasm. Thereby, oleuropein has caused to $\mathrm{Ca}^{2+-}$ associated cytotoxicity and arresting the cell cycle. Moreover, the effect of olive leaf and oleuropein on VGSC-mediated cell movement has been evaluated, and promising results have been obtained.

Keywords: olive, oleuropein, cancer, metastasis, ion channels

\section{IS-12}

\section{THERAPEUTIC SILENCING OF NA 1.5 CHANNEL IN METASTATIC BREAST CANCER MODELS IN VITRO AND IN VIVO}

Mumin Alper Erdogan ${ }^{1,2}$

${ }^{1}$ Izmir Katip Çelebi University, Faculty of Medicine, Department of Physiology, Izmir, Turkey

${ }^{2}$ UT MD Anderson Cancer Center, Department of Experimental Therapeutics, Houston, TX, USA

Breast cancer (BCa) is the most common cancer among women worldwide. The major reason for patient death is due to metastasis and resistance to current therapies. Thus, the development of novel targeted therapeutic strategies is urgently needed to prolong patient survival. Ion channels, including voltagegated ion channels (VGSC), could similarly have a significant role in cancer. VGSC is a group of ion channels that has been correlated with BCa. Importantly, VGSC activity contributes to many cellular behaviors integral to metastasis. In a recent study, authors determined upregulation of the sodium channel $\mathrm{Na}_{\mathrm{v}} 1.5$ and its neonatal spliced form $\left(\mathrm{nNa}_{\mathrm{v}} 1.5\right)$ in metastatic $\mathrm{BCa}$ cells, tissues and breast tumors from patients who had a recurrence. The aim of the current study was to reveal molecular mechanisms underlying the effects of $\mathrm{Na}_{\mathrm{v}} 1.5$ and $\mathrm{nNa}_{\mathrm{v}} 1.5$ down-regulation and investigate the effects on $\mathrm{BCa}$ in vitro and in vivo models. In this study, the human breast cancer cell lines (MDA-MB-231, MDA-MB-468 and MCF-7) were used. $\mathrm{Na}_{\mathrm{v}} 1.5, \mathrm{nNa}_{\mathrm{v}} 1.5$ and Control non-silencing small interfering RNAs (siRNA) were employed for therapy. As in vitro experiments, cell proliferation and drug resistance, colony formation, invasion, migration, wound-healing tests, apoptosis and cell cycle analysis by flow cytometry, western blot and Real-Time/RT-PCR analysis were performed. Effects of $\mathrm{Na}_{\mathrm{v}} 1.5$ siRNA treatments in nanoliposomal carriers on both tumor growth and metastasis capacity of $\mathrm{BCa}$ were evaluated by performing xenograft orthotopic $\mathrm{BCa}$ and lung metastasis models (BLI imaging) in vivo. Our results showed that expression of $\mathrm{Na}_{\mathrm{v}} 1.5$ and $\mathrm{nNa}_{\mathrm{v}} 1.5$ mRNAs are higher in MDA-MB-231 cells compared to MCF7. Specific $\mathrm{Na}_{\mathrm{v}} 1.5$ siRNA treatments caused a significant reduction in cell proliferation, colony formation, invasion/migration/wound-healing capacity and drug resistance (Paclitaxel) in metastatic BCa cells $(\mathrm{p}<0,0001)$. However, $\mathrm{Na}_{\mathrm{v}} 1.5$ siRNAs did not effect cell proliferation in normal breast epithelium cell line MCF10A. These siRNAs also increased the level of apoptosis and caused G1 cell cycle arrest in MDA-MB-231 cells $(\mathrm{p}<0,0001)$. Targeting of $\mathrm{Na}_{\mathrm{v}} 1.5$ and $\mathrm{nNa}_{\mathrm{v}} 1.5$ channels in an in vivo orthotopic breast cancer and lung metastasis models inhibited tumor growth, tumor weight and lung metastasis in two different mice models $(\mathrm{p}<0,0001)$. Our western blot data suggested that $\mathrm{Na}_{\mathrm{v}} 1.5$ and $\mathrm{nNa}_{\mathrm{v}} 1.5$ may enhance tumorigenesis and metastasis through the upregulation of pro-tumorigenic, metastatic proteins and pathways in $\mathrm{BCa}$. In conclusion, it was revealed with all these results that $\mathrm{Na}_{\mathrm{v}} 1.5$ and $\mathrm{nNa}_{\mathrm{v}} 1.5$ channels have an important role in the metastasis, development and progression of breast cancer. Overall, targeting $\mathrm{Na}_{\mathrm{v}} 1.5$ and $\mathrm{nNa}_{\mathrm{v}} 1.5$ by systemically administered siRNA is a viable approach and may be beneficial to breast cancer patients. Keywords: Breast Cancer, Metastasis, Nanoliposom, $\mathrm{Na}_{\mathrm{v}} 1.5$, siRNA

\section{IS-13}

REPURPOSING OF ION CHANNEL BLOCKERS: NEW HOPE FOR BREAST CANCER METASTASIS

\section{Didem Keleş}

Izmir University of Economics, Vocational School of Health Services Medical Laboratory Techniques 35330 Balcova, Izmir, Turkey

Breast cancer is one of the major health problems of the modern world and there is a great challenge in providing effective and non-cytotoxic therapy, especially for metastatic breast cancer. In this regard, the discovery of ion channels offers much novel potential. Ion channels are pore-forming transmembrane proteins that allow the flow of ions such as sodium, potassium, hydrogen, calcium, and chloride, inside and outside of the cell. More recently, functional ion channels have been found in metastatic cancer cells of epithelial origin, such as breast cancer, prostate cancer, colon cancer, and lung cancer. Remarkably, Na 1.5, NHE1, TRPM7, and ORAI1 are found to be upregulated in breast tumors and highly correlated with cancer metastasis. Particularly, upregulation of voltage gated sodium channels (VGSCs) which mediate influx of $\mathrm{Na}^{+}$in response to membrane depolarization, make the plasma membranes of metastatic cells excitable and, thus, hyperactive. Moreover, blocking these channels (using antagonist, siRNA or antibody) suppressed metastatic cell behaviours, e.g. lateral motility, transverse migration, invasion, secretory/endocytic membrane activity, etc.

Today, the clinically approved drugs targeting ion-channel activity comprise local anesthetics (lidocaine, tetracaine), antiarrhythmic drugs (ranolazine, riluzole, diltiazem, verapamil), antiepileptic drugs (phenytoin), antihypertensive drugs (manidipine, amlodipine, felodipine, cilnidipine) etc. Recent findings revealed that approved ion channel blockers such as lidocaine, ranolazine, and phenytoin strongly inhibit cell invasion and migration in breast cancer cells and, therefore, these drugs are excellent candidates for repurposing as an anti-metastatic agent in clinical implications. However, the underlying mechanisms are still unclear. In conclusion, further understanding of the anti-metastatic mechanisms underlying ion channel blocking agents will provide to develop new and safer therapy strategies for breast cancer metastasis.

Keyword: Ion Channels, Drug Repurposing, Breast Cancer Metastasis Acknowledgements: This research was supported in by a grant (no. 115S504) from The Scientific and Technological Research Council of Turkey (TUBITAK).

\section{IS-14}

LARGE CONDUCTANCE CA2 ${ }^{+}$-ACTIVATED K ${ }^{+}$CHANNELAUXILIARY SUBUNITS IN GLIOBLASTOMA

\section{Gyorgy Panyi}

Department of Biophysics and Cell Biology, Faculty of Medicine, University of Debrecen, Hungary

$\mathrm{KCa} 1.1$ (MaxiK, BK) is a voltage- and $\mathrm{Ca}^{2+}$-activated $\mathrm{K}^{+}$-channel. $\mathrm{KCa} 1.1$ is the major $\mathrm{K}^{+}$channel in various cancer cells e.g. glioblastoma multiforme. KCa1.1 is proposed to provide a $\mathrm{Ca}^{2+}$-dependent hyperpolarization mechanism required for the maintenance of $\mathrm{Ca}^{2+}$ signaling in response to mitogens, tissue factors (e.g. ATP), to promote cell cycle progression and invasion. The function of KCa1.1 is heavily influenced by a transcript variant of the pore-forming alpha subunit and associated beta subunits. Our aim was to characterize the beta subunit expression in glioblastoma multiforme and in U87-MG, a glioblastoma cell line.

U87-MG cell line was maintained under normal cell culture conditions. Glioblastoma tissue samples were obtained from the Dept. of Neurosurgery, University of Debrecen, under appropriate ethical controls (ethical approval obtained). Tissue samples were homogenized and primary glioblastoma cells were confirmed using glial fibrillary acidic protein (GFAP) staining. RT-PCR was used to identify the expression of the ion channels and auxiliary subunits 
at mRNA level. Functional expression of the ion channels was studied using single cell (patch-clamp) electrophysiology, whole-cell currents were separated to individual components using biophysical (voltage protocols) and pharmacological (ion channel activators and inhibitors) tools.

RT-PCR showed that KCa1.1 beta 2, beta 3 and beta 4 subunits are expressed on mRNA level in U-87-MG cells. The functional expression of the beta subunits in the $\mathrm{KCa} 1.1 /$ beta subunit complexes was analyzed using electrophysiology in combination with pharmacological agents. The pharmacological assay of the whole cell currents tested the sensitivity of the currents to paxilline, lithocholic acid, arachidonic acid, and iberiotoxin. The combination of the activation/ inhibition pattern resulted in the conclusion that $\mathrm{KCa} 1.1$ beta 2 or beta 3 subunit may be expressed in U-87-MG. We strongly suspect that beta 3 is expressed on the cell surface, as whole-cell currents show only a minimal inactivation after $200 \mathrm{~ms}$ depolarization, and this current phenotype excludes the presence of beta 2 subunits. Similar results were found using human primary glioblastoma cells isolated from patient samples.

Our conclusion is that glioblastoma cells express a specific combination of pore forming and auxiliary subunits of the large-conductance $\mathrm{Ca} 2+$-activated $\mathrm{K}+$ channel. This may allow subunit composition-specific targeting of the ion channel in glioblastoma.

\section{IS-15}

RANOLAZINE AND RILUZOLE COMBINATION IN PROSTATE CANCER: ANTI-METASTATIC POTENTIAL

\section{Seyhan Altun}

Istanbul Kultur University, Faculty of Science and Letters, Departments of Molecular Biology and Genetics, Istanbul, Türkiye

Studies have shown that metastases are the life-threatening factor in prostate cancer, as in other cancers. Especially, upregulation of voltage-gated $\mathrm{Na}^{+}$channels (VGSCs) in the cell membrane plays a role in the progression of primary tumor to metastasis. VGSCs with increased expression are responsible for migration and invasion, which are the main steps of metastasis. It has been determined as in vitro and in vivo that some ion channel blockers, which block upregulated VGSCs and are used in the treatment of different diseases, suppress the movement of cancer cells and inhibit metastasis. Inhibiting the movement of cancer cells with these drugs that show pharmacological effects by suppressing VGSCs will open a new field of treatment for anti-metastatic potential. Ranolazine (RNL), which is clinically used in the treatment of angina pectoris, has a therapeutic effect on heart pain, contraction and dysfunction by blocking sodium channels. On the other hand, Riluzole (RIL) is a neuroprotective drug, especially used in the ALS disease, which inhibits sodium and calcium flow and plays a role in the treatment by suppressing glutamate release. These VGSC blockers have higher activity in the hypoxic environment than the normoxic environment. The aim of this study is to determine whether the combined treatment using two VGSC blockers together had a synergistic effect on the migration of Dunning model high metastatic prostate cancer cells, in other words, to determine their contribution to antimetastatic potential and to search the potential for developing a new treatment protocol against prostate cancer metastasis.

The effects of RNL $(2.5 \mu \mathrm{M}, 5 \mu \mathrm{M})$, RIL $(2.5 \mu \mathrm{M}, 5 \mu \mathrm{M})$ and RNL + RIL $(2.5+2.5$ $\mu \mathrm{M}, 5+2.5 \mu \mathrm{M})$ on the proliferation of Dunning model rat prostate cancer MATLyLu and AT-2 cells with different metastatic features were examined. The effects on the anti-metastatic potential were realized by "wound heal" method in high metastatic Mat-LyLu cells.

According to the results obtained, when both RNL and RIL were administered alone, there was no significant change in the proliferation of the cells. Combined administration of drugs $(5+5 \mu \mathrm{M})$ to MAT-LyLu cells reduced cell proliferation by $30 \%$. TTX which is a VGSC blocker, blocked the lateral movement of MaTLyLu cells by $23 \%$. RNL and RIL which did not affect cell proliferation, produced inhibition of cell migration ( $48 \mathrm{~h}$ ) both alone and in combination at varying rates $(5-14 \%)$. The combination of RNL and RIL which was searched for the first time, produced inhibition of migration of prostate cancer cells under normoxic conditions, but did not produce a synergistic effect. These promising results suggest that the combined effects of RNL and RIL on anti-metastatic potential should be searched in detail in hypoxic conditions and in vivo experimental models.

Keywords: prostate cancer, ranolazine and riluzole combination, anti-metastatic potential.

\section{IS-16}

RILUZOLE: ANTI-INVASIVE EFFECT OF A VOLTAGE-GATED SODIUM CHANNEL BLOCKER ON RAT PROSTATE CANCER CELLS $\underline{\text { Nahit Rizaner }}{ }^{1,2}$, Sercan Uzun ${ }^{3}$, Scott P Fraser $^{1}$, Seyhan Altun $^{3,4}$,

Mustafa B A Djamgoz ${ }^{1,2}$

${ }^{1}$ Department of Life Sciences, Neuroscience Solutions to Cancer Research Group, Sir Alexander Fleming Building, Imperial College London, South Kensington Campus, London SW7 2AZ, U.K.

${ }^{2}$ Cyprus International University, Biotechnology Research Centre, Haspolat, Mersin 10, North Cyprus, Turkey.

${ }^{3}$ Department of Biology, Faculty of Science, Istanbul University, Vezneciler, Istanbul 34134, Turkey.

${ }^{4}$ Department of Molecular Biology and Genetics, Faculty of Science and Letters, Istanbul Kultur University, Istanbul, 34158, Turkey.

Metastasis is the main cause of death in most cancer patients. Voltage-gated sodium channels (VGSCs) are functionally expressed in prostate cancer ( $\mathrm{PCa}$ ), as well as in several other carcinomas, where their activity potentiates various metastatic cell behaviours. Accordingly, VGSC blocking pharmacological agents have been proposed as potential anti-cancer drugs. In the present study, we investigated the anti-metastatic potential of the neuroprotective VGSC blocking drug, riluzole, at clinical doses. The strongly metastatic rat PCa Mat-LyLu cells were used as a model.

Exposure of Mat-LyLu cells to hypoxia $\left(24 \mathrm{~h}, 2 \% \mathrm{O}_{2}\right)$ significantly increased the mRNA expression of Nav1.7, the predominant VGSC $\alpha$-subunit expressed in rat and human $\mathrm{PCa}$, by $400 \%$. Under normoxic conditions, riluzole $(2.5-5 \mu \mathrm{M})$ had no effect on Nav1.7 mRNA expression, whilst in hypoxia $\left(24 \mathrm{~h}, 2 \% \mathrm{O}_{2}\right)$ significant reduction of $\sim 40 \%$ was observed. On the other hand, immunocytochemistry and confocal imaging showed no effect of riluzole $(2.5 \mu \mathrm{M})$ on sub cellular distribution of VGSC $\alpha$ protein levels.

Riluzole treatment $(5 \mu \mathrm{M})$ under both normoxic and hypoxic $\left(2 \% \mathrm{O}_{2}\right)$ conditions had no effect on cell viability and proliferation. Hypoxia $\left(2 \% \mathrm{O}_{2}\right)$ alone had no significant effect on Matrigel invasion. In contrast, riluzole and TTX ("internal control') treatments caused significant reduction in invasion by $>45 \%$.

We conclude (1) that that riluzole can significantly suppress the invasiveness of PCa cells especially under normoxic conditions; (2) that it is possible to control invasiveness without killing cancer cells; and (3) riluzole could be 'repurposed as a safe anti-anti-metastatic drug.

Keywords: Hypoxia, voltage-gated sodium channel, prostate cancer, metastasis, riluzole, tetrodotoxin.

\section{IS-17}

PROTEOLYTIC CLEAVAGE OF VOLTAGE GATED SODIUM CHANNELS BY MATRIX METALLOPROTEINASE-9

Murat Sipahi

Dokuz Eylul University, School of Medicine, Department of Medical Biochemistry, Izmir, Turkey

Voltage-gated sodium channels (VGSCs) are glycosylated transmembrane proteins which are made up of a pore forming $\alpha$-subunit (VGSC $\alpha$ ) and at least two auxiliary $\beta$-subunits (VGSC $\beta$ ). They are expressed in conventionally 'excitable' cells in neurons and muscle cells to create action potentials as well as 'nonexcitable' cells such as endothelial cells, lymphocytes, osteoblasts, fibroblasts, and renal tubular epithelial cells. Beside their physiological role, aberrant VGSC activity has been shown to participate in oncogenic potential in a range of human carcinomas.

Breast cancer is the most common type of cancer after lung cancer in women Metastasis, a multistage process in which extracellular matrix is modulated and degradaged by proteolytic enzmyes, is the major cause of death in breast cancer patients. Among these proteolytic enzymes, matrix metalloproteinases (MMPs) play a key role in the digestion of extracellular matrix components and in signal transduction pathways.

The primary goal of this study is to investigate whether MMP-9 cleavages $\mathrm{Na}_{\mathrm{v}} 1.5$ and $\beta_{1}$, the most abundant VGSC subunits in breast cancer. For this purpose, we incubated GST-tagged recombinant human $\beta_{1}$ and GST-tagged recombinant human truncated form of $\mathrm{Na}_{\mathrm{v}} 1.5$ proteins with active and pro forms of MMP-9, respectively, and performed western blot in order to detect any possible cleavaged fragments. Immunblotting the membrane with $\beta_{1}$ specific antibody recognized two fragments in $\beta_{1}$ /active-MMP-9 while GST specific antibody detected fragments both $\beta_{1}$ /active-MMP-9 and $\beta_{1} /$ pro-MMP-9 groups. On the other hand cleavage effects of MMP-9 on $\mathrm{Na}_{\mathrm{v}} 1.5$ was immunologically be detected only with GST 
specific antibody since $\mathrm{Na}_{\mathrm{v}} 1.5$ antibody was unable to recognize truncated form of the rh- $\mathrm{Na}_{\mathrm{v}} 1.5$. Degredation products were detectable only in $\mathrm{Na}_{\mathrm{v}} 1.5 /$ activeMMP-9 group which indicates cleavage fuction of MMP-9 on $\mathrm{Na}_{v} 1.5$.

Silver staining was performed to detect any other cleavaged fragments which were unable to be recognized immunologically. In silver stained gels cleaved bands were more than their western blot counterparts both in $\beta_{1}$ /active-MMP-9 and $\mathrm{Na}_{\mathrm{v}} 1.5$ /active-MMP-9 groups.

In conclusion we showed in vitro cleaveage effects of MMP-9 on $\mathrm{Na}_{\mathrm{v}} 1.5$ and $\beta_{1}$. Our data will shed light on the contribution of MMP-9 on metastatic potential in breast cancer via cleaving $\beta_{1}$ and $\mathrm{Na}_{\mathrm{v}} 1.5$.

Keywords: Voltage-gated sodium channels, Matrix Metalloproteinase-9, Breast cancer

Acknowledgements: This research was supported in by a grant (no. 115S504) from The Scientific and Technological Research Council of Turkey (TUBITAK).

\section{IS-18 \\ WHAT'S NEW IN CANCER IMMUNOTHERAPY?}

Dicle Güç

Hacettepe University, Cancer Institute, Department of Basic Oncology, Ankara, Turkey

The dream of the educating immune system specifically to kill cancer cells become real recently by the advance of our understanding the interaction between tumor and immune system. Cancer immunotherapy aims to augment the weak immune response to cancer cells. Treatment of the cancer patients by immunologic approaches attract attention of the scientist for many years since, conventional therapies, chemotherapy and radiotherapy, are harmful to both tumor cells and some healthy cells and tissues. However, immune response against tumor may be specific to tumor antigens and will not injured the other cells. Furthermore, antitumor immune response to a specific antigen can be recalled by the cells of the adaptive immune system. Stimulation of active host immune response to tumors (active immunotherapy) or transfer of immune effectors, $\mathrm{T}$ cells or antibodies, in to patients (passive immunotherapy) are among the immunotherapeutic strategies. Immune system developed some checkpoints such as cytotoxic T-lymphocyte antigen 4 (CTLA-4) and programmed cell death 1 (PD-1), in order to protect bodies own cells and cancer cells escape from the immune system by using these checkpoints. Immune checkpoint blockade has shown remarkable benefit in the treatment of a range of cancer types by increasing antitumor immunity.

\section{IS-19}

\section{DEVELOPMENT OF BIOBETTER ANTIBODIES FOR NEXT- GENERATION CANCER THERAPEUTICS}

\section{Sibel Kalyoncu}

İzmir Biomedicine and Genome Center, İzmir, Turkey

Monoclonal antibodies are one of the most important biological drugs being developed for targeted therapy of cancer. There are currently more than 80 antibodies approved on the market and even more on clinical trials. More than $90 \%$ of approved antibody drugs are full-length ( $\operatorname{IgG}$ ) and the rest is antibody fragments where all or some parts of constant regions are eliminated while essential antigen binding region is preserved. It is very well-known that antibody fragments usually show similar binding properties as their full-length versions with even better biophysical properties. Compared to full-length antibodies, antibody fragments have some advantages for therapeutic use: (i) lower immunogenicity due to lack of constant regions (ii) higher tumor penetration (iii) cheaper and larger scale production with bacteria (iv) availability of various in vitro screening technologies to improve several characteristics. Today, number of antibody fragments on preclinical and clinical trials are increasing faster than before due to their advantages.

In this talk, next-generation anti-angiogenesis antibody fragments will be introduced. Anti-angiogenesis therapy is still one of the most powerful strategy to treat several types of cancer due to its known success. Recombinant-DNA technologies and protein engineering techniques are used to design and engineer several antibody fragments in two different formats. They are expressed in bacteria, purified, characterized and tested in zebrafish angiogenesis model to investigate their biobetter properties. If their biobetter properties are confirmed, these next-generation antibody fragments can pave the way for more effective cancer therapeutics.

Keywords: Antibody, antibody fragments, cancer, angiogenesis, recombinant protein

\section{IS-20 \\ CLINICAL TRIALS: CHALLENGES AND VALIDATION FROM TRIAL CONDITIONS TO REAL LIFE}

Uğur Önsel Türk

Dokuz Eylul University, İzmir, Turkey

International regulatory authorities, such as the FDA and EMA, consider the quality standard (internal validity) of the clinical trial to be the basis for a license (pivot) in the licensing process. Whereas, a pivot experiment is usually performed in a selected population, which represents only a certain part of the population. Certainly, main focus of clinicians are their patients. Herein, clinicians are concerned about the extent to which the clinical trial results conducted on the selected population are valid for their patients, and how adaptable the results are to patients in practice (external validity). Another concern of clinicians is the real clinical benefit of the effect of the clinical trial. Yet, trials' statistical significance and $p$ value may not be an indicator of the actual clinical efficacy of the drug. Clinicians treat patients, not numbers. Consequently, the idea of "the right medicine, in the right time to the right patient" can only be performed through clinical drug trials with appropriate design by industry, regulatory authorities and researchers, with a patient perspective when choosing endpoints.

Keywords: Clinical Trials, Oncology, External Validation

\section{IS-21}

\section{CLINICAL TRIALS IN ONCOLOGY: WHY ARE THEY NECESSARY?}

Işık Tuğlular

Ege University, Faculty of Medicine, Department of Medical Pharmacology, İzmir, Turkey

Cancer is a leading cause of death in the world. Although mortality rates have been partially reduced due to early treatment and / or the development of new treatments, the overall incidence of cancer is increasing due to aging of the population, environmental reasons (tobacco, alcohol, food) or widespread discovery and screening techniques.

Therefore, cancer continues to be an important public health problem in social and economic terms.

Progress in the field of research has gained strong momentum in recent years, and efforts to find new, innovative therapies within this framework have increased significantly. However, drug development is a complex process in oncology. Due to insufficient effectiveness or unfavorable safety profile, very few products can be licensed compared to the number of clinical trials performed.

Therefore, the importance of clinical trials in oncology is increasing day by day. Clinical trials also help us find new paths to prevent and detect cancer and improve the quality of life for people during and after treatment. Clinical trials are the most valid way and key to making progress against cancer.

Recently, clinical trials in oncology have recently made significant progress and developed valid strategies.

Keywords: Clinical Trials, Oncology

\section{IS-22}

\section{THE EFFECTS OF HYPOXIA IN CHONDROSARCOMAS}

\section{Leyla Didem Kozacı}

Ankara Yıldırım Beyazıt University, Medical Faculty, Medical Biochemistry, Ankara, Turkey

Chondrosarcomas are malignant cartilage-producing tumours showing mutations and changes in gene expression in metabolism related genes. In chondrosarcoma cells metabolic processes are largely deregulated. Conventional chondrosarcoma type is the most frequent $(85 \%)$ one, followed by dedifferentiated type $(10 \%)$. Chondrosarcomas are associated with poor clinical outcomes and treated by surgery since these tumours show limited response to conventional chemo- and radiotherapy $(1,2)$. Unlike other malignant bone tumours including osteosarcomas and Ewing sarcomas, conventional and dedifferentiated chondrosarcomas mainly affect people in the $4^{\text {th }}-7$ th decade of life (3). Although, the cells of origin of conventional and dedifferentiated chondrosarcomas are still not clearly defined they most likely develop from mesenchymal stem and progenitor cells (MSPC) exhibiting multipotent differentiation potential. Thus, chondrosarcomas not only express several proteins as MSPC markers but also chondrogenic markers or markers of other mesenchymal lineage commitment. Adult articular cartilage also 
contains MSPCs which are predominantly localized in the superficial zone (SZ) and undergo proliferation upon onset of OA. There is accumulating evidence that chondrosarcomas show similar epigenetic dysregulation as OA (4).

Oxygen level play vital role in regulating cell behaviour including stem or tumour cells. Hypoxia is important in normal development and disease progression, including the growth of solid tumours such as chondrosarcomas. The hypoxia inducible factors (HIFs) are the key mediators of the cellular response to hypoxia. HIFs are composed of an oxygen-dependent $\alpha$ subunit and an oxygen-independent $\beta$ subunit. The $\alpha$-subunit has three isoforms, HIF- $1 \alpha$, HIF- $2 \alpha$, and HIF- $3 \alpha$. Alpha subunit degradation occurs in a posttranslational prolyl hydroxylation manner under normoxia (5).

HIF-1 $\alpha$ is a well-known facilitator of proliferation and angiogenesis in solid tumours and in chondrosarcomas specifically (6). In human chondrosarcoma cells, expressions of HIF-1 $\alpha$ signalling cascades has been shown to increase (7). Hypoxia related genes HIF-1 $\alpha$ and its downstream targets were found to be upregulated in high grade compared to low grade chondrosarcomas, and their high expression was correlated with a shorter metastasis free survival (8). It is known that hypoxia-induced apoptosis is also mediated by HIF-1 $\alpha$. Therefore, HIF- $1 \alpha$ has been accepted as a good candidate for cancer therapy as it plays a vital role in regulating tumour survival and growth under hypoxic condition.

Chemoresistance of chondrosarcoma may be due to slow proliferation, multidrug resistance protein 1 (MDR1) overexpression, poor vascularity and dense hyaline ECM. Under moderate hypoxic conditions (5\% O2) radiation resistance of chondrosarcoma cell lines were significantly higher compared to standard cell culture conditions $(21 \% \mathrm{O} 2)$ suggesting hypoxia to be a determining factor for the responsiveness of chondrosarcoma to radiation (3). Chemoresistance of chondrosarcoma has been ascribed several factors such as (1) the phenotypic properties; hyaline cartilaginous matrix surrounding the cells prohibiting access to the cells, poor vascularization, and a slow division rate $(9,10)$, antiapoptosis or prosurvival pathways (9) multidrug resistance pump activity. In recent years, several advances have been made in identifying potential targets for clinical trials targeting multiple active pathways in chondrosarcoma such as active survival pathways, HIF1a expression and growth plate signalling pathways including antiapoptotic signalling and retinoblastoma pathway $(11,12)$.

Kubo et al. suggested that HIF-1 $\alpha$ protein might be a more useful prognosis marker in determining chondrosarcoma patient prognosis than the histological grade of the tumour (6). Hypoxia promotes expression and function of both HIF$1 \alpha$ and HIF- $2 \alpha$ which can be assessed by downstream gene expression, western blot, luciferase assay and ELISA using osteosarcoma models. More studies are required to clarify the role of hypoxia and HIF-1 $\alpha$ to develop therapeutic strategies by targeting HIF-1-alpha or molecules that can activate or activated by HIF-1-alpha in high grade chondrosarcomas, characterized by resistance to chemo- and radiotherapies.

Keywords: Hypoxia,chondrosarcoma, HIF1alpha

\section{REFERENCES}

1. van Maldegem AM, Gelderblom H, Palmerini E, Dijkstra SD, Gambarotti M, Ruggieri P, Nout RA, van de Sande MA, Ferrari C, Ferrari S, Bovee JV, Picci $\mathrm{P}$, Outcome of advanced, unresectable conventional central chondrosarcoma, Cancer 2014,120(20):3159-3164

2. Italiano A, Mir O, Cioffi A, Palmerini E, Piperno-Neumann S, Perrin C, Chaigneau L, Penel N, Duffaud F, Kurtz JE, Collard O, Bertucci F, Bompas E, Le CA, Maki RG, Ray CI, Blay JY, Advanced chondrosarcomas: role of chemotherapy and survival, Ann. Oncol. 2013,24(11):2916-2922

3. Boehme KA, Schleicher SB, Traub F, Rolauffs B. Chondrosarcoma: A Rare Misfortune in Aging Human Cartilage? The Role of Stem and Progenitor Cells in Proliferation, Malignant Degeneration and Therapeutic Resistance Int. J. Mol. Sci. 2018, 19(311):1-26

4. Steinberg J, Ritchi GRS, Roumeliotis TI, Jayasuriya RL, Clark MJ, Brooks RA, Binch ALA, Shah KM, Coyle R, Pardo M, et al. Integrative epigenomics, transcriptomics and proteomics of patient chondrocytes reveal genes and pathways involved in osteoarthritis. Sci. Rep. 2017, 7, 8935

5. Zeng W, Wan R, Zheng Y, Singh SR, and Wei Y. Hypoxia, Stem cells and Bone Tumor Cancer Lett. 2011, 313(2): 129-136

6. Kubo T, Sugita T, Shimose S, Matsuo T, Arihiro K, Ochi M. Expression of hypoxia-inducible factor-1alpha and its relationship to tumour angiogenesis and cell proliferation in cartilage tumours. J Bone Joint Surg Br. 2008, 90:364-370

7. Lee HP, Lin CY, Shih JS, Fong YC, Wang SW, Li TM, Tang CH. Adiponectin promotes VEGFA-dependent angiogenesis in human chondrosarcoma through PI3K, Akt, mTOR, and HIF- $\alpha$ pathway. Oncotarget. 2015, 6:3674636761

8. Boeuf S, Bovee JV, Lehner B, Hogendoorn PC, Richter W, Correlation of hypoxic signalling to histological grade and outcome in cartilage tumours, Histopathology 2010, 56 (5): 641-651

9. Bove'e JV, Hogendoorn PC, Wunder JS, et al. Cartilage tumours and bone development: molecular pathology and possible therapeutic targets. Nat Rev Cancer 2010,10(7):481-8. 91.

10. David E, Blanchard F, Heymann MF, et al. The bone niche of chondrosarcoma: a sanctuary for drug resistance, tumour growth and also a source of new therapeutic targets. Sarcoma 2011,2011:932451

11. Update on Targets and Novel Treatment Options for High-Grade Osteosarcoma and Chondrosarcoma Jolieke G. van Oosterwijk, Jakob K. Anninga, Hans Gelderblom, Anne-Marie Cleton-Jansen, Judith V.M.G. Bovée, Hematol Oncol Clin N Am 27 (2013) 1021-1048

12. Hypoxia-inducible factor 1-alpha and vascular endothelial growth factor in cartilage tumours E. Kouvaras, Z. Christoni, I. Siasios, K. Malizos, G. K. Koukoulis \& M. Ioannou. Biotechnic \& Histochemistry, 94:4, 283-289, 2019

\section{IS-23 \\ HYPOXIA INDUCIBLE FACTOR: A NOVEL PROGNOSTIC BIOMARKER FOR HEAD AND NECK CANCERS}

\section{Görkem Eskiizmir}

Manisa Celal Bayar University, Department of Otolaryngology-Head and Neck Surgery, Manisa, Turkey

In the tumor microenvironment, several metabolic changes are developed depending on the interaction between cancer cells and stromal cells. Hypoxia is the most important of these metabolic changes. It $(p \mathrm{O} 2<10-15 \mathrm{mmHg}$ ) is referred to as the imbalance between the amount of oxygen level that is required for tissues and the amount of oxygen level that is supplied (1).

Currently, hypoxia is determined in the tumor microenvironment of several solid cancers such as breast, brain, cervix, prostate, rectum and head and neck cancers(1-4). Moreover, it has been known that approximately $50-60 \%$ of locally advanced tumors have heterogeneously distributed and different amount of hypoxic areas (1). The major mechanisms for the development of hypoxia are: (i) hypoxia due to the restriction of diffusion: It develops due to the distance of cancer cells to microvessels ( $>70$ micron), (ii) perfusion-limited hypoxia: It is a result of functional and structural deformities of tumor microvessels (amorphous and chaotic vascular system), (iii) hypoxia that is related to the insufficiency in tissue oxygenation: Patient general condition, cancer-related cachexia, and anemia are the major factors.

Hypoxia might play a key role in the development of genetic instability and disruption of gene expression in cancer cells, tumor invasion ability and aggressive character, radio/chemotherapy treatment resistance and metastasis (5-8). In the tumor microenvironment, the development of hypoxia leads to activation of several signaling pathways and production of hypoxia-related biomolecules including hypoxia-inducible factors (HIF's), which are also referred to as the "hypoxia sensors". These proteins are transcriptional complexes made of two heterodimers: HIF-a and -b $(\mathbf{9 , 1 0})$. To date, three different HIF isoforms have been described: HIF-1, -2 , and -3 . Healthy cells in physoxic microenvironments continuously synthesize HIF, however these proteins are rapidly hydroxylated as a result of an oxygen-dependent reaction catalyzed by specific hydroxylase enzymes. Hydroxylated HIF protein is a substrate for von Hippel-Lindau protein; therefore degraded through the ubiquitination process. On the other hand, when oxygen levels in the tumor microenvironment are reduced, hydroxylation of HIF does not occur, which results in an elevation in HIF concentration. Thus, the increase in HIF levels may alter the gene functions which affect cancer cell apoptosis, epithelial-mesenchymal-transition, invasion capacity, angiogenic signaling, and energy metabolism (9-11).

A systematic review reported that these biomarkers were frequently detected in patients with head and neck cancer and indicated poor prognosis (12). Moreover, a recently published meta-analysis, which was particularly related to HIF expression, demonstrated that increased HIF-1a expression associated with tumor size, stage, lymph node metastasis, and overall survival (13). In this presentation, the predictive and prognostic biomarker roles of HIF will be discussed particularly from the field of head and neck cancers.

Keywords: Head and Neck cancer, tumor microenvironment, hypoxia, hypoxia inducible factor.

\section{REFERENCES}

1. Vaupel P. Tumor microenvironmental physiology and its implications for radiation oncology. Semin Radiation Oncol 2004; 14: 198-206.

2. Hoogsteen IJ, Marres HA, Bussink J, van der Kogel AJ, Kaanders JH. Tumor 
microenvironment in head and neck squamous cell carcinomas: Predictive value and clinical relevance of hypoxic markers. A review. Head Neck 2007; 29: 591-604.

3. Janssen HL, Haustermans KM, Balm AJ, Begg AC. Hypoxia in head and neck cancer: How much, how important? Head Neck 2005; 27: 622-38

4. Kim Y, Lin Q, Glazer PM, Yun Z. Hypoxic tumor microenvironment and cancer cell differentiation. Curr Mol Med 2009; 9: 425-34.

5. Vaupel P, Harrison L. Tumor hypoxia: Causative factors, compensatory mechanisms, and cellular response. Oncologist 2004; 9 (suppl 5): 4-9.

6. Bussink J, Kaanders JH, van der Kogel AJ. Tumor hypoxia at the microregional level: clinical relevance and predictive value of exogenous and endogenous hypoxic cell markers. Radiother Oncol 2003; 67: 3-15.

7. Vaupel P. Hypoxia and aggressive tumor phenotype: implications for therapy and prognosis. Oncologist 2008; 13 (suppl 3): 21-6.

8. Eskiizmir G. Tumor Microenvironment in Head and Neck Squamous Cell Carcinomas. Turk Arch Otorhinolaryngol 2015; 53: 120-7

9. Semenza GL. HIF-1, O(2) and the 3 PHDs: how animal cells signal hypoxia to the nucleus. Cell 2001;107:1-3.

10. Semenza GL. Hypoxia-inducible factors in physiology and medicine. Cell 2012;148:399-408.

11. Weidemann A, Johnson RS. Biology of HIF-1alpha. Cell Death and Differentiation 2008;15:621-7.

12. Swartz JE, Pothen AJ, Stegeman I, Willems SM, Grolman W. Clinical implications of hypoxia biomarker expression in head and neck squamous cell carcinoma: a systematic review. Cancer Med 2015;4:1101-16.

13. Zhou J, Huang S, Wang L ve ark. Clinical and prognostic significance of HIF$1 \alpha$ overexpression in oral squamous cell carcinoma: a meta-analysis. World J Surg Oncol 2017;18:104.

\section{IS-24}

\section{EXPERIMENTAL MODELS IN PERITONEAL CARCINOMATOSIS}

Aras Emre Canda

Dokuz Eylul University School of Medicine Department of Surgery, İzmir, Turkey

Peritoneal carcinomatosis (PC) or peritoneal metastases (PM) is an advanced stage of cancer and it is associated with a poor prognosis. It was considered untreatable and terminal stage of the disease; however, cytoreductive surgery (CRS) and hyperthermic intraperitoneal chemotherapy (HIPEC) become a potential treatment strategy for those patients. Cytoreductive surgery aims the removal of the all visible tumor including peritonectomy procedures, organ resections was first initiated by Sugarbaker (1). The most important thing in CRS may be the residual, especially microscopically, disease after the resections. Sugarbaker describes the importance of the microscopical residual disease as "It's what the surgeon doesn't see that kills the patient" (2).

Peritoneal metastases may present synchronously at the same time during the diagnosis of the primary tumor or may present as a metachronous disease. Most accepted hypothesis is the seed and soil hypothesis in which peritoneal metastases develops as a result of the growth of tumor that invades through the serosal lining of the organ including colon, stomach, intestines and tubes and ovaries allowing the exfoliation and shedding of malignant cells intraperitoneally. $(3,4)$. Also, it may develop iatrogenically after cancer surgery due to tumor manipulation during the surgical procedure including iatrogenic perforation of the tumor, transection of lymphatics or blood vessels, inappropriate surgical dissection. [5-9]. Figure 1a. shows PMs in small bowel mesentery and serosa originated from colon cancer. After successful removal of the all possible visible tumors (peritonectomy procedures and organ resections) to extend the macroscopical tumor removal to the microscopical clearance we introduce hyperthermic intraperitoneal chemotherapy (HIPEC) by special hyperthermia pumps for 30-90 minutes (Figure 1b).

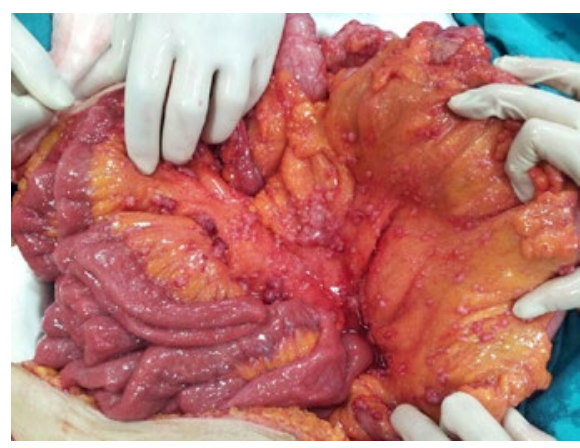

Figure 1a: Multiple small peritoneal metastases at the intestinal mesentery and serosa

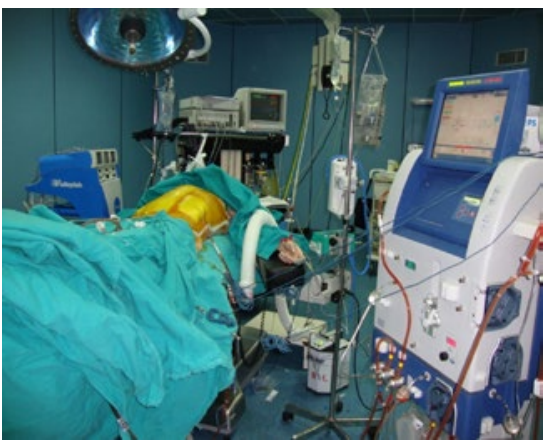

Figure 1b. Application of HIPEC by hyperthermia pump Intraperitoneal chemotherapy after tumor debulking is a concept proven in clinical trials for management of patients with ovarian cancer $(10,11)$. Intraperitoneal chemotherapy aims targeting tumors within the peritoneal cavity. It also offers pharmacokinetic advantages when compared to intravenous administration of the same chemotherapeutic by allowing higher concentrations of the drug in the peritoneal cavity with lower toxicity (12-14). Estimated penetration of the chemotherapeutic agent into the cancer cells during intraperitoneal administration is less than $1 \mathrm{~mm}$ diameter which may be increase up to $2.5 \mathrm{~mm}$ by using hyperthermia at $42-43^{\circ} \mathrm{C}(15,16)$.

Recently other intraperitoneal chemotherapy method is described: Pressurized intraperitoneal aerosol chemotherapy (PIPAC). It is a minimal invasive procedure and currently applied to the patients with unresectable PMs or in a neoadjuvant setting. In this method after laparoscopically placement of the trocars chemotherapy is introduced into the abdominal cavity as aerosol under $12 \mathrm{mmHg}$ pressure. Both aerosol state of the drug and $12 \mathrm{mmHg}$ pressure adds physical advantage to drug penetration in to the cancer tissues (Figure 2).

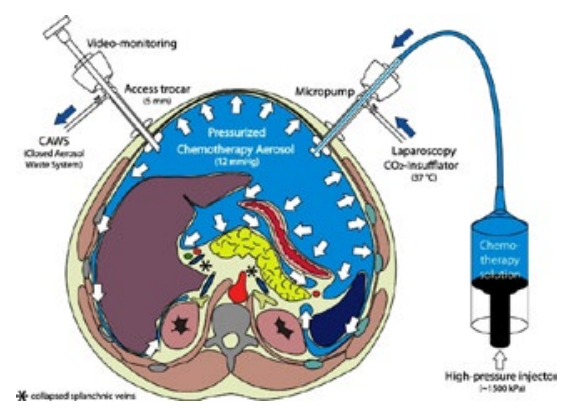

Figure 2a: Schematic description of the application of pressurized intraperitoneal aerosol chemotherapy (PIPAC)

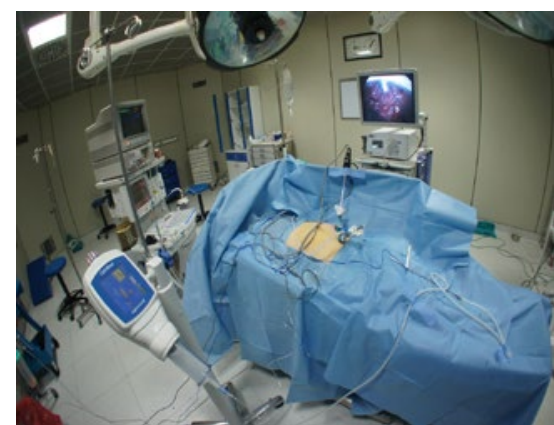

Figure 2b: Application of PIPAC in a patient with unresectable PMs originated from ovarian cancer

There are lots of unanswered and unproved points in the treatment of PMs with CRS and HIPEC. We need more experimental models, cell culture researches and clinical data. In this presentation I will summarize the experimental models for the treatment of PMs.

Outline of the experimental models:

1. In silico: Mathematical and numerical models of the computational fluid dynamics $(C F D)$ simulation can be done. Main research areas are aerosol properties (droplet size, speed), effect of temperature and pressure, nebulizer 
design, HIPEC machine design, electrostatic precipitations.

2. In vitro

- Test boxes

- Inverter bladder model

Main research areas are; aerosol properties, structural drug integrity, tissue penetration. Peritoneal cavity is a dynamic space and respiratory movements, intestinal peristalsis, changing gravity by patient's position, intraabdominal physiological pressure are the main variables.

3. In vivo animal models

- Large animal (rabbit and pig)

- Small animal

Main research areas are pharmacokinetics and pharmacodynamics, tissue penetration, antitumor efficacy, toxicity, complications, optimizing the dose and defining the therapeutic window.

4. Cell cultures

-2D models

-3D models

- Microfluidic systems

- Oranoids

5. Experimental HIPEC and PIPAC models

Keywords: Peritoneal carcinomatosis, experimental models, HIPEC, PIPAC, cytoreductive surgery, cell culture

\section{REFERENCES}

1. Sugarbaker PH. Surgical management of peritoneal carcinosis: diagnosis, prevention and treatment. Langenbecks Arch Chir 1988;373(3):189-96.

2. Sugarbaker PH. It's what the surgeon doesn't see that kills the patient. J Nippon Med Sch 2000;67(1):5-8.

3. Paget $\mathrm{S}$ : The distribution of secondary growths in cancer of the breast. Lancet 1889; $133: 571-573$

4. Hart IR, Fidler IJ. Role of organ selectivity in the determination of metastatic patterns of B16 melanoma. Cancer Res 1980;40:2281-2287.

5. Koppe MJ, Boerman OC, Oyen WJG, et al. Peritoneal carcinomatosis of colorectal origin: Incidence and current treatment strategies Ann Surg 2006;243:212-222.

6. Welch JP, Doanldson GA. The clinical correlation of an autopsy study of recurrent colorectal cancer. Ann Surg 1979;189:496-502.

7. Gilbert JM. Distribution of metastases at necropsy in colorectal cancer. Clin Exp Metastasis 1983;1:97-101.

8. Weiss L, Grundmann E, Torhorst J, et al. Haematogenous metastastic patterns in colonic carcinoma: An analysis of 1541 necropsies. J Pathol 1986;150:195203.

9. Sugarbaker PH, Yu W, Yonemura Y. Gastrectomy, peritonectomy, and perioperative intraperitoneal chemotherapy: The evolution of treatment strategies for advanced gastric cancer. Semin Surg Oncol 2003;21:233-248.

10. Armstrong DK, Bundy BN, Baergen R, et al. Randomized phase III study of intravenous (IV) paclitaxel and cisplatin versus IV paclitaxel, intraperitoneal (IP) cisplatin and IP paclitaxel in optimal stage III epithelial ovarian cancer (OC): A gynecologic oncology group trial (GOG 172). Proc Am Soc Clin Oncol 2002;21:803.

11. Tiersten AD, Liu PY, Smith HO, et al. Phase II evaluation of neoadjuvant chemotherapy and debulking followed by intraperitoneal chemotherapy in women with stage III and IV epithelial ovarian, fallopian tube or primary peritoneal cancer: Southwest oncology group study S0009. Gynecol Oncol 2009; 112:444-449.

12. R.L. Dedrick, C.E. Myers, P.M. Bungay, V.T. DeVita Jr. Pharmacokinetic rationale for peritoneal drug administration in the treatment of ovarian cancer, Cancer Treat Rep 1978;62:1-11.

13. Markman M. Strategies to examine new compounds for intraperitoneal use in ovarian cancer. Int J Gynecol Cancer 2008; 18:33-35.

14. Wolinsky JB, Colson YL, Grinstaff NW. Local drug delivery strategies for cancer treatment: gels, nanoparticles, polymeric films, rods, and wafers. J Control Release 2012;159:14-26.

15. Li XF, Carlin S, Urano M, Russell J, Ling CC, O’Donoghue JA. Visualization of hypoxia in microscopic tumors by immunofluorescent microscopy. Cancer Res 2007;67:7646-7653.

16. Klaver YL, Hendriks T, Lomme RM, et al. Hyperthermia and intraperitoneal chemotherapy for the treatment of peritoneal carcinomatosis: an experimental study. Ann Surg 2011;254:125-130.

17. Solass W, Kerb R, Mürdter T, et al. Intraperitoneal chemotherapy of peritoneal carcinomatosis using pressurized aerosol as an alternative to liquid solution: first evidence for efficacy. Ann Surg Oncol 2014;21(2):553-9.

\section{IS-25}

\section{MODULATION OF $\mathrm{CA}^{2+}$ SIGNALING FOR CANCER THERAPY}

\section{Ahmet Aydın}

Department of Pharmaceutical Toxicology, Faculty of Pharmacy, Yeditepe University, Kayışdağı, Istanbul. ahmet.aydin@yeditepe.edu.tr, İstanbul, Turkey

Calcium $\left(\mathrm{Ca}^{2+}\right)$ is a secondary messenger in survaving cells. It is involved in a various cellular processes including cell growth, apoptosis, differentiation, metabolism, muscle contraction, neuronal plasticity and gene transcription. It is also involved in different pathological conditions including cancer. Some hallmarks of cancer progression are controlled by $\mathrm{Ca}^{2+}$ signaling. These are cell proliferation, angiogenesis, invasion and metastasis. $\mathrm{Ca}^{2+}$ concentration within the cells are strictly regulated. There is a 10,000-fold gradient between extracellular and cytosolic $\mathrm{Ca}^{2+}$ concentration. Elevation of cytoplasmic $\mathrm{Ca}^{2+}$ level can trigger many types of cell toxicity. It can be caused by promoting $\mathrm{Ca}^{2}$ influx into cells or inhibiting $\mathrm{Ca}^{2+}$ efflux from the cytoplasm. Major calcium channels, pumps, exchangers and sensors are responsible for regulating the $\mathrm{Ca}^{2+}$ level in mammalian cells. These are transient receptor potential (TRP) channels, voltage-gated calcium channels (VGCC), ligand-gated ionotropic P2X receptors, mechanosensitive piezo channels, store-operated $\mathrm{Ca}^{2+}$ entry pathway mediated by stromal interaction molecule 1 (STIM1) sensor, ORAI1 channels, the plasma membrane $\mathrm{Ca}^{2+}$-ATPase (PMCA), sarcoplasmic/endoplasmic reticulum $\mathrm{Ca}^{2+}-$ ATPase (SERCA), and golgi network secretory pathway $\mathrm{Ca}^{2+} / \mathrm{Mn}^{2+}$-ATPase (SPCA). Recent studies have proved the role of $\mathrm{Ca}^{2+}$ signaling for growth and development of some type of cancers such as brain and breast. Specific channels and pumps for $\mathrm{Ca}^{2+}$ transportation into and out of the cells are altered in cancers. There are some in vitro and/or in vivo studies and clinical trials which study the role of these systems in different type of cancers. After discovering the role of these transport systems, specific target for pharmacotherapeutic agents to treat or to diagnose cancer cases will be possible. This presentation will summarize published data about the $\mathrm{Ca}^{2+}$ transport systems, their possible role in cancer development and possible therapeutic target on these transport systems.

\section{IS-26}

\section{VACUOLE MEMBRANE PROTEIN 1 (VMP1)'S ROLE IN BREAST CANCER DEVELOPMENT}

Arsalan Amirfallah ${ }^{1,5}$, Adalgeir Arason ${ }^{2,5}$, Oskar Por Johannsson ${ }^{4}$, Bjarni A Agnarsson $^{3,6}$, Rosa Bjork Barkardottir ${ }^{2,5}$, Inga Reynisdottir ${ }^{1,5}$

${ }^{1}$ Cell Biology Unit at the Pathology Dept., Landspitali - The National University Hospital of Iceland, 101Reykjavík, Iceland.

${ }^{2}$ Molecular Pathology Unit at the Pathology Dept., Landspitali - The National University Hospital of Iceland, 101 Reykjavik, Iceland.

${ }^{3}$ Pathology Dept, Landspitali - The National University Hospital of Iceland, 101 Reykjavik, Iceland.

${ }^{4}$ Dept. of Oncology, Landspitali - The National University Hospital of Iceland, 101 Reykjavik, Iceland.

${ }^{5}$ Biomedical Center, Laeknagardur, Vatnsmyrarvegur 16, 101 Reykjavik, Iceland. ${ }^{6}$ Faculty of Medicine, University of Iceland, Saemundargata 2, 101 Reykjavik, Iceland.

Breast cancer is the most common cancer in women worldwide. Fusion genes result from genomic structural changes can result in changes in gene expression that affect tumour development. The objective of this study was to identify a gene with a role in breast cancer by analyzing gene fusions.

Fusion genes, identified through bioinformatics pipelines in breast cancer cell lines and tumors, were compared. The fusion genes in common were confirmed by qRT-PCR and sequencing, and then filtering criteria were applied. The DNA and mRNA quantity of the chosen individual genes, available from public databanks, were correlated to nominate candidates. The expression of the top ranked gene was measured by qRT-PCR in two Icelandic breast cancer cohorts, an exploratory cohort $(n=141)$ and a validation cohort $(n=277)$, and subsequently correlated with clinicopathological characteristics and survival. The results were followed-up in breast cancer cohorts from The Cancer Genome Atlas $(\mathrm{n}=818)$ and METABRIC $(\mathrm{n}=2509)$.

The mRNA levels of the top ranked gene Vacuole Membrane Protein 1 (VMP1) were significantly higher in breast tumor tissue than normal tissue, and its expression was significantly higher in HER2 positive tumours than HER2 negative tumours in all four cohorts analyzed.

High expression of VMP1 associated with breast cancer specific survival (BCSS) in cohort 1 (hazard ratio $(\mathrm{HR})=2.31$, CI 1.27-4.18) and METABRIC (HR = 
1.26, CI 1.02-1.57) and also after adjusting for HER2 expression in cohort 1 $(\mathrm{HR}=2.03$, CI 1.10-3.72). The results suggest that an increase in mRNA levels of VMP1 is a potential marker of poor prognosis in breast cancer, particularly in HER2 positive cases. Further studies are needed to elucidate how VMP1 could affect pathways supportive of tumorigenesis.

Keywords: Breast cancer, gene fusions, gene expression, VMP1, tumor development

\section{IS-27}

\section{ORGANOIDS AS AN EX VIVO MODEL IN CANCER RESEARCH}

Gizem Calibasi-Kocal

Dokuz Eylul University, Institute of Oncology, Department of Translational Oncology, Izmir, Turkey.

The organoid term is commonly used to describe ex vivo multicellular structures, which include the specific cell types of an organ and harbor its in vivo organization. These multicellular structures derive from stem cells such as adult stem cells, which have differentiation ability to generate any cell type. Early work of stem cell derived organoids performed for intestinal tissue and cortical tissue, and they showed promising capacity to organize into complex in vivo like structures. But today, organoids have been presented for various tissues such as intestine, stomach, lung, liver, prostate and brain. Therefore, they can be used to mimic developmental processes and disease states, as well as improve cell-based therapies. During the development process of organoid based studies, researchers started to work on organoids from primary tumors to understand tumor biology and solve problems on in vitro drug testing. Organoid models offer various experimental advantages for modelling cancer and understanding tumor biology, such as long term culturing, differrent tissue compartments and gene manipulation. Additionally, while organoids are very promising models to study of cancer, disadvantages arise from the lack of essential systems such as the vascular, lymphatic and immune systems; and their architecture cannot always present the organ structure as same as in vivo. Overall, organoids are important to model cancer and use them for understanding tumor biology and testing drugs. Keywords: Organoid, cancer, ex vivo model

\section{IS-28 \\ REPROGRAMMING OF ORAL SQUAMOUS CELL CARCINOMA IN RESPONSE TO METABOLIC DRUGS}

\section{Seniz Inanc Surer}

Dokuz Eylul University, Institute of Health Sciences, Department of Medical Biochemistry, Izmir, Turkey.

Oral squamous cell carcinoma (OSCC), an aggressive and drug-resistant cancer type, is sixth cancer worldwide and a subtype of head and neck cancers. Even chemo/radiotherapy strategies are effective for early-stage, 5 years survival rates are significantly lower for the patients with the advanced stage of oral squamous cell carcinoma. Drug repositioning is a drug designing method in which available FDA-approved drugs are determined for their potent effects in different diseases especially cancer. Metformin, used in the treatment of type 2 diabetes, inhibits the mitochondrial complex I and recent studies have shown that Metformin has a great potential as an anticancer agent. Dichloroacetate (DCA) which is effective on lactic acidosis, is a small kinase inhibitor of mitochondrial pyruvate dehydrogenase kinase-1 (PDK-1). In this context, Metformin and DCA as metabolic drugs have potential in cancer therapy. This study aimed to investigate the effects of Metformin and Dichloroacetate on cell viability, HIF-1 $\alpha$, and PDK1 expressions, and mitochondrial metabolism in the oral squamous cell carcinoma cell line (UPCI-SCC-131).

UPCI-SCC-131 cells were treated with Metformin and Dichloroacetate at different concentrations for 72 hours under normoxic/hypoxic conditions and $\mathrm{IC}_{50}$ values were determined. The synergism of Metformin and DCA were analyzed according to the Chou-Talalay combination index method. Gene and protein expression levels of HIF-1 $\alpha$ and PDK-1 were examined by Real-Time PCR and Western Blot, respectively. Besides, the effects of drugs on metabolism were evaluated by Seahorse XF Analyzer.

Combination analysis showed that Metformin and DCA in UPCI-SCC-131 cells had a synergistic effect on cell viability. HIF-1 $\alpha$ and PDK-1 expression levels were significantly decreased in Metformin/Dichloroacetate-treated cells. Also, metabolic flux experiments showed that Metformin shifted cellular phenotype into the glycolytic pathway, whereas Dichloroacetate shifted into the energetic pathway.

We conclude that the data we have obtained will contribute to the development of new therapeutic combinations which have anti-tumorigenic properties for the treatment of the oral squamous cell carcinoma metabolism in the future.

Keywords: Oral cavity cancer cell line, Metformin, Dichloroacetate, HIF-1 alpha, PDK-1

Acknowledgments: This research was supported in by a grant (no. 118S576) from The Scientific and Technological Research Council of Turkey (TUBITAK).

\section{IS-29}

\section{THIOL DISULFIDE HOMEOSTASIS AND CANCER}

\section{Ozcan Erel}

Ankara Yıldırım Beyazıt Univ, Med. Fac. \& Ankara City Hospital, Med. Biochem. Lab., Ankara, Turkey

BACKGROUND and AIM: Dynamic thiol disulphide homeostasis has a crucial role for several functions including detoxification, oxidation of proteins, antioxidant defense, apoptosis and cellular signal transduction mechanism. There is also growing evidence demonstrating that abnormal thiol disulphide homeostasis status that is involved in the pathogenesis of several benign and some malignant conditions. Determination of serum thiol disulfide homeostasis of patients with cancer and comparison of the obtained results with those of healthy subjects were aimed.

MATERIALS AND METHODS: Serum native thiol, total thiol and disulfide levels were measured with a recently developed automated method. The ratios were calculated. The results of the groups were compared and the relationship among the measured parameters and clinical stages of the patients were determined.

RESULTS: Generally, native thiol, total thiol, and disulfide levels were significantly lower in patients with cancer than those of healthy groups and there were significant correlations among the parameters and the stages of the diseases. CONCLUSION: Low levels of thiol-disulfide parameters and the weakened homeostatic status may be related to tumor aggressiveness and may predict a poor outcome for patients with cancer. These changes may be seconder to the diseases.

\section{IS-30}

PROTEIN AND DNA DAMAGE IN RELATION TO ENVIRONMENTAL POLLUTANT LEVELS AND GENETIC POLYMORPHISMS IN KIDNEY, STOMACH AND BREAST CANCER PATIENTS

Hilmi Orhan ${ }^{1}$, Sinan Süzen ${ }^{2}$, Rasih Kocagöz ${ }^{1}$, İlgen Onat ${ }^{1}$, Merve Demirbügen ${ }^{2}$, Burak Turna $^{3}$, Koray Atilla ${ }^{4}$, Levent Yeniay ${ }^{3}$, Yiğit Tiftikçioğlu ${ }^{3}$, Banu Sarsık ${ }^{3}$, Osman Zekioğlu ${ }^{3}$, Murat Özdemir ${ }^{3}$, Berk Göktepe ${ }^{3}$, Gürdeniz Serin ${ }^{3}$, Ersin Gür ${ }^{3}$ ${ }^{1}$ Ege University, Faculty of Pharmacy, ${ }^{2}$ Ankara University, Faculty of Pharmacy, ${ }^{3}$ Ege University, Faculty of Medicine, ${ }^{4}$ Dokuz Eylül University Faculty of Medicine, İzmir, Turkey

Environmental pollutants such as organochlorine pesticides (OCPs), polychlorinated biphenyls (PCBs) and polybrominated diphenyl ethers (PBDEs), so called persistent organic pollutants (POPs) have been known to interfere various ion channels in organism, which is the main mechanism of action especially for OCPs. Furthermore, all PCBs and several congeners of OCPs and PBDEs were recently listed as "carcinogen" by the IARC depending on evaluation of epidemiological studies. On the other hand, there have been very little data on the relation between various cancers and tissue burden of these toxicants. In majority of the human studies on a possible association between POPs and cancers, exposure data have been based on statement-based interviews, which potentially impair the accuracy and reliability of quantitative assessment In order to accurately assess whether environmental exposure to POPs increase risk of kidney, stomach and breast cancers, tumour tissues as well as blood and urines were collected from surgically operated patients. Cellular DNA and protein oxidative damage markers (8-OHdG and dityrosine, respectively), have also been analysed in the patient and healthy control groups, and assessed whether there are changes in these parameters. The data suggest that majority of POPs in cancerous tissues were associated with cancers in patients, while they are less conclusive in blood of the same patients. DNA and protein damage markers were found to be higher in urines of kidney cancer patients compared to healthy volunteers, although inter-individual variability obscured statistical significances. Current findings confirmed that glutathione S-transferase theta1 (GSTT1) nullpolymorphism is a risk factor for kidney cancer, and cytochrome P450 1A1 
(CYP1A1) is a risk factor for stomach cancer. Data suggest that environmental exposure to POPs may induce tumour initiation and/or progression in humans however, blood concentrations of the same pollutants do not adequately reflect tissue concentrations except dichlorodiphenyldichloroethylene (DDE), the major metabolite of the notorious organochlorine pesticide dichlorodiphenyltrichloroethylene (DDT). Possible role of interaction of POPs with ion channels in cancer initiation and/or progression remain to be explored.

Keywords: Persistent organic pollutants, cancer, human, DNA damage, biomarker, genetic variation

\section{IS-31}

CLINICALANALYSIS OF GERMLINE CELLAND SOMATIC VARIANTS

\section{Altug Koc}

Department of Medical Genetics, Faculty of Medicine, Department of Translational Oncology, Institute of Oncology, Dokuz Eylul University Izmir, Turkey

Next-generation Sequencing (NGS) gives the opportunity of massive parallel sequencing of DNA fragments. The technology is a revolution for detection of germline variations. Because of its high sequencing capacity, it could investigate more than thousands of genes at the same time in an individual as in exome sequencing. In addition, more than hundreds of cases may be investigated in the same NGS run. At the end of sequencing, there are enormous number of germline variations as the products of new technology. And classification of them according to their clinical significance is needed. Variant databases, interpretation guidelines such as the guideline of American College of Medical Genetics and Genomics $(\mathrm{ACMG})$ and prediction softwares largely overcome difficulties in variant classification. Another major progress achieved by NGS is the identification of tumor genotype (somatic variations) which enables precision medicine via somatic variation targeted immunotherapies. The sensitivity of NGS is increased by the reading counts of the targets. Even, increased counts and sensitivity enable the identification of somatic variants of a solid tumor in plasma. The approach is called liquid biopsy and it is very useful for monitorization of tumor genotype evolution in an individual. In addition, exhaled breath condensate studies open a new era in non-invasive sample collection. Although, the great sensitivity comes with false positive results and again the challenge of variant interpretation which is more difficult in somatic variations. Cancer, because of its nature, produces huge amounts of genetic variations. Unfortunately, publicly available, somatic variation databases are restricted. Commercial concerns are more pronounced. There are also some technical challenges due to tumor heterogeneity. New methods such as cell phenotyping could lead to genotyping or transcriptome identification cell by cell.

\section{IS-32}

\section{SYSTEMATIC COMPARISON OF SOMATIC ANALYSIS PIPELINES}

Erşen Kavak

Genomize

Optimization of mapping algorithm to call indels on the read-ends, and comparison of the variant calling algorithms (Mutect2 and Freebayes which are used in our system) with the optimization of mapping algorithm by calculating sensitivity, specificity and accuracy.

\section{IS-33}

\section{ONLINE TOOLS FOR ENRICHMENT ANALYSIS AND COMPOUND- TARGET DETERMINATION}

\section{Zerrin Ișık}

Dokuz Eylül University, İzmir, Turkey

A traditional pipeline of disease treatment development starts with the analysis of transcriptome data and identification of potential candidates. The following stages are the enrichment analysis of candidate proteins in terms of their functions, employing metabolic and signaling pathways. After obtaining limited number of proteins that might be potential treatment targets, the compound-target databases are used to identify experimental or validated compounds binding to the given proteins.

The first session of this course will explain usage of highly comprehensive functional enrichment tools: Enricher, DAVID. The next session will demonstrate identification of potential compounds in online databases such as DrugBank, STITCH, BindingDB, PubChem. Both sessions are not requiring any coding knowledge, the participant only needs a personal computer with an internet connection.

Keywords: enrichment analysis, compound-target search, pathway analysis

\section{IS-34}

\section{INTEGRATIVE MODELING OF BIOMOLECULAR COMPLEXES}

Ezgi Karaca

Izmir Biomedicine and Genome Center

Izmir International Biomedicine and Genome Institute, İzmir, Turkey

Life is operated at the nanometer scale through orchestrated communications of biomolecules. By dissecting this nanoworld, we can acquire a fundamental understanding of how biological macromolecules function, how they are related to disease-linked pathways and how to design drugs targeting them. This understanding led to the birth and rise of Structural Biology, the study of the structures of biomolecules and their complexes at atomic resolution.

In her talk, Dr. Karaca will briefly introduce the basic Structural Biology techniques and the data types acquired with them. This will be followed by a comprehensive explanation of how to incorporate Structural Biology data into biomolecular simulations, especially into docking. Finally, she will talk about her past and latest research on integrative modeling, expanding on the development of the most cited data-driven docking program, HADDOCK.

Keywords: docking, integrative modeling, structural biology, molecular modeling

\section{IS-35}

\section{MOLECULAR DOCKING APPLICATION IN CANCER RESEARCH}

\section{Nazlı Mert Özüpek}

Department of Basic Oncology, Graduate School of Health Sciences, Dokuz Eylül University, İzmir, Turkey

Drug development is the approach of finding targets and effects (agonist or antagonist) to clinical applications. According to the report of Tufts Center for the Study of Drug Development published in 2014, the 11-year drug development cost increased by $145 \%$ to $\$ 2.6$ billion. Since drug design and development process causes many failures, takes many years and have much uncertainty, computer-based screening tools are of great importance to predict the possible drugs or biologicals. Molecular docking is a process to estimate the structure of the ligand (small molecule, drug, biological, etc.) within the target (protein) and to determine the binding strength, accurately. According to the recent studies, there are more than 10 algorithms (programmes) used for docking. Although significant progress in curative treatment, cancer is still one of the most important cause of death all around the world. In accordance with the reports of World Health Organization (WHO), one-third of the cancer-caused deaths are preventable. Finding the potential cancer drug by using molecular docking studies is very crucial. The beginning of target-based approaches (molecular docking or de novo design-fragnomics) is target selection from the databases obtained from in-vitro, in-vivo, ex-vivo models and RNA interference screen, etc. Protein Data Base (RCSB PDB) is one of the most important databases for achieving the 3D version of the cancer target which contain more than 1 TB of Structure Data for Proteins, DNA, and RNA. Potential Drug Target Database (PDTD) is other important the protein database which can be used for getting information about the position and conformation of ligand (drug) within the cancer protein targets. In cancer studies, the second step of molecular docking is ligand preparation. One of the most important ligand preparation programs is openbabel. After these process, potential drugs (ligands) for cancer prevention/treatment dock to potential proteins (or genes) (target) by using molecular docking tools. One of the most common docking tool is AutoDock Vina. Docking scores give information of the possible positions and conformations about the cancer drug. Although molecular docking is promising method for cancer drug design and development, further in-vivo and in-vitro analysis are recommended.

Keywords: Drug development, molecular docking, oncology

\section{REFERENCES}

1. Mohs, R. C., \& Greig, N. H. (2017). Drug discovery and development: Role of basic biological research. Alzheimer's \& Dementia: Translational Research \& Clinical Interventions, 3(4), 651-657.

2. Tufts Center for the Study of Drug Development (2014). Cost to Develop and Win Marketing Approval for a New Drug Is \$2.6 Billion 
3. Yuriev, E., \& Ramsland, P. A. (2013). Latest developments in molecular docking: 2010-2011 in review. Journal of Molecular Recognition, 26(5), 215-239.

4. Berman, H. M., Westbrook, J., Feng, Z., Gilliland, G., Bhat, T.N., Weissig, H., Shindyalov, I.N., \& Bourne, P. E., (2000) The Protein Data Bank Nucleic Acids Research, 28: 235-242.

5. Gao, Z., Li, H., Zhang, H., Liu, X., Kang, L., Luo, X., ... \& Jiang, H. (2008). PDTD: a web-accessible protein database for drug target identification. BMC bioinformatics, 9(1), 104.

6. Trott, O., \& Olson, A. J. (2010). AutoDock Vina: improving the speed and accuracy of docking with a new scoring function, efficient optimization, and multithreading. Journal of computational chemistry, 31(2), 455-461.

\section{IS-36}

\section{RADIOMICS AND CLINICAL TRANSLATION}

\section{Emine Acar}

İzmir Katip Çelebi University, İzmir, Turkey

Tumor heterogeneity is difficult to quantify. For example, biopsies are invasive and do not represent the full extent of genotypic and phenotypic tumor variations. Although intra-tumoral heterogeneity occurs at very small spatial scales, its macroscopic signatures can be observed using by diagnostic imaging techniques. The advantage of diagnostic imaging is that it is non-invasive. It is also a valuable advantage to visualize the entire tumor area. Imaging is already often repeated during treatment in routine practice, on the contrary of histopathologic examinations, which are still challenging to implement into clinical routine.

Since the start of 18F-FDG PET clinical application, there has been a rapid growth in the number of studies that employed standardized uptake value (SUV) as a primary imaging biomarker for uptake heterogeneity quantification. In addition to SUV measurements, metabolic tumor volume is another biomarker that has been reportedly shown to have prognostic significance for clinical outcomes such as the development of distant metastasis and loco-regional recurrence. As an alternative, several studies proposed quantitative imaging features, such as radiomic features, as a surrogate to overcome such pitfalls. Textural features, a type of radiomic features, are extracted from statistical matrices based on local intensity spatial distribution relationships. And it is widely used in the last decade.

Radiomics is a complex process that involves several steps. It begins with acquisition of high-quality images, from which a region or voxel of interest is identified and segmented either manually or automatically. Once the segmentation is completed, dedicated software then extract quantitative features from the obtained volumes to produce a report, which is inserted into a database and integrated with other data such as clinical information, genomic profiles, serum markers, or histology data. Next comes the evaluation of these data through advanced statistics and bioinformatics.

Key words: clinical information, feature, texture analysis, radiomics

\section{IS-37 \\ ACCESS AND APPLICATION TO GENOMIC DATABASES WITH R \& PYTHON}

Asim Leblebici ${ }^{1}$, Femin Yalçın²

${ }^{1}$ Dokuz Eylul University, Institute of Health Sciences, Department of Translational Oncology, İzmir, Turkey

${ }^{2}$ Izmir Katip Celebi University, Department of Engineering Sciences, İzmir, Turkey

Public databases have been established over the internet in order to enable researchers to easily access existing biological data and share new results.

SRA (Sequence Read Archive), GDC (Genomic Data Commons) and GEO (Gene Expression Omnibus) under NCBI (National Center for Biotechnology Information) based in the United States; ENA (European Nucleotide Archive), Array Express and Expression Atlas under the European-based EBI (European Bioinformatics Institute), and DDBJ (DNA Data Bank of Japan) under the Japanese Institute of Genetics are the most known and widely used web-based databases. These organizations work together to collect and share nucleotide sequence information.

$\mathrm{R}$ ( $\mathrm{R}$ Project) is an open-source programming language with strong packages for statistical computations and graphs, and also widely used in biostatistics and bioinformatics analysis. Python is one of the most popular programming languages and fast to learn and widely used. Anaconda distribution is used to install Python and is available in all software environments.
Genomic databases can be accessed through their sites as well as R and Python packages. With the "TCGAbiolinks" package for Genomic Data Commons (GDC), data on the portal can be accessed and various analyses are performed. GEO database with microarray and transcriptomic data can be accessed via R-GEOquery package. Also ArrayExpress and Expression Atlas data can be accessed respectively via (same name data repository) ArrayExpress and ExpressionAtlas package of R. GDC data can be accessed via "pytcga" package and GEO database can be accessed via GEOparse package of Python. Expression Atlas data can be accessed via "genexpatlas" package of Python.

Keywords: R, Python, Genomic databases, software package

Table: $\mathrm{R}$ and Python package for accessing genomic data portal

\begin{tabular}{ccc}
\hline Portal Name & R package & Python package \\
\hline GDC & TCGAbiolinks & pytcga \\
GEO & GEOquery & GEOparse \\
ExpressionAtlas & ExpressionAtlas & geneexpatlas \\
\hline
\end{tabular}

\section{IS-38}

\section{AN INTRODUCTION TO LOC DEVICES}

Hüseyin Üvet

Yıldız Technical University, İstanbul, Turkey

The recent advances in lab-on-chip systems have shown a great potential in-vitro medical applications. Microfluidic-based technology offers a convenient platform for cellular analyses of biological systems, as the small scale of micro-channels and devices allows producing scalable system architecture. Their inexpensive composition makes them a potential candidate for large scale production. Microfluidic technology covers not only the material phenomena but also the technology for manipulating and controlling the components as micro size particles in microscopic size artificial capillaries. Therefore, the integration of these technologies with lab-on-a-chip applications could be useful in the automation of cell manipulation for important areas such as single cell analysis, manipulation and treatment. In example, Integration of cell treatment steps is crucial to develop lab-on-a-chip devices for analysis of cell constituents, cell lysis and cell culture. The experimental results show that microfluidic technology provides a significant advantage in the production of mammalian embryos. Besides those vital concepts, cell fusion and nuclear transplantation are also hot topics.

In this course, demonstrations of understanding of microfluidic devices, calculating diffusion, settling, wetting will be discussed. Distinguishing microfluidic components, fabrication process will be briefly explained as well as design microfluidic systems for applications like particle counting, separation, protein analysis will be discussed under the light of fundamental applications. On completion of the course, participants will be able to gain a broad insight into lab-on-a-chip technology. They will have broad information on the current literature about microfluidics while they gain knowledge on important microfluidics system fabrication guidelines.

Acknowledgement:

This work is funded by The Scientific and Technological Research Council of Turkey (TUBITAK) under the project number 116E743.

Keywords: Lab-on-a-chip, microfluidics, nanofabrication, on-chip sensor technology

\section{IS-39}

\section{DISEASE MODELING IN MICROFLUIDIC ORGAN-ON-CHIPS FOR PRECLINICAL STUDIES}

Ozlem Yesil Celiktas

Department of Bioengineering, Faculty of Engineering, Ege University 35100 Bornova-İzmir, Turkey

The development and approval of new therapies have not been accelerated due to several reasons among which the lack of preclinical models stands as a significant factor. Key parameters related to molecular, cellular and physiological features of human disease progression have to be considered while developing such models. Although animal models have been widely used, interspecies differences such as absorption, tissue distribution, metabolism, and excretion of pharmaceutical agents and toxins result in contradictions in terms of replication of animal studies to human randomized trials and translation to clinical trials. Organ chips have arisen as a powerful tool to overcome these limitations. Organ-on-chips populated 
by human primary cells and/or stem cells can recapitulate in vivo organ level physiology and pathophysiology by recreating tissue and organ level functions in vitro. Liver cancer metastasis and lung cancer models will be elaborated and cancer-on-chip models used to assess the efficacy of drug therapies will be discussed. In the short to medium term, more efforts are anticipated in engineering advanced microfluidic systems to develop organ-on-chip platforms for predictive translation of preclinical findings into clinical studies.

Keywords: microfluidics; organ-on-chip; disease modeling; cancer models

\section{IS-40}

\section{LAB-ON-A-CHIP DEVICES FOR MOLECULAR AND CELLULAR DRUG SCREENING}

Ahu Arslan-Yıldız

Department of Bioengineering, Izmir Institute of Technology, İzmir, Turkey

Microfluidic systems offer promising experimental platforms for varied chemical and biological lab-on-a-chip (LoC) applications, therefore microfluidics attracted significant attention over the past decade [1]. Because of the advantages provided by miniaturization, low volume and sample requirement, and also controlled and easily manipulated microenvironment; microfluidics are heavily used for tissue engineering, regenerative medicine, drug development and drug screening applications. The conventional drug screening techniques include 2D cell cultures, animal studies and high-throughput screening platforms which are highly expensive, time consuming and non-efficient. To overcome these obstacles, LoC microfluidic systems are commonly preffered for drug development and drug screening purposes. For the purpose of drug screening; systems integration brings together the microfluidics and microfabrication concept with molecular or cellular biology tools to form functional LoC devices. Although there is a rapid development in the field of LoC drug screening, there is still unmet need. Therefore, development of sophisticated microfluidic technologies; and also further developments in cellular and molecular tools are required [2-4].

Here, this contribution summarizes our efforts in microfluidic drug screening platforms; (i) rapid prototyping and microfabrication of microfluidic devices, (ii) on-chip drug screening based on 3D cell culture, and (iii) molecular drug screening approach via ion channel integrated biomimetic platforms.

Keywords: Microfluidics, Lab-on-a-Chip (LoC), Drug Screening, 3D Cell Culture, Molecular Level Drug Screening, hERG ion channel

References

1. Mark, D., Haeberle, S., Roth, G., Stetten, F., Zengerle, R. Chemical Society Reviews, 39, 1153-1182 (2010).

2. Duffy, D.C., McDonald, J.C., Schueller, O.J.A., Whitesides, G.M. Analytical Chemistry, 70, 4974-4984 (1998).

3. Bilginer, R., Arslan Yildiz, A., Biomimetic Model Membranes as Drug Screening Platforms / Biomimetic Lipid Membranes: Fundamentals, Applications, and Commercialization (2019) 225-247, Springer Nature Switzerland AG.

4. Onbas, R., Bilginer, R., Arslan Yildiz, A., On-chip Drug Screening Technologies for Nanopharmaceutical and Nanomedicine Applications / Nanopharmaceuticals: Principles and Applications, Springer Nature Switzerland AG (in press).

\section{IS-41}

\section{DIGITAL HOLOGRAPHY IN CANCER RESEARCH}

Ali Anil Demircali

Yildiz Technical University, Mechatronics Engineering Department, Istanbul, Turkey

The recent advances in digital holopraphic systems have shown a great potential candidate for imaging of cell biology, cancer research, cell cycle analyses and stem cell research. Optical technology provides a convenient platform for a high-precision and accurate 3D model of a single cell. Due to depth information and stiffness are cruical parameters to investigating whether the cell is healty or cancerous, digital holographic tecniques such as Michelson and Mach-Zehnder can give up to sub-nano resolution. Even their initial test setup cost of is expensive, it is ahead of today's imaging technologies. Optical technology includes not only the light phenomena but also the technology for manipulating as optic tweezers and plant biology. Meanwhile, with the integration of optical technologies in biomedical fields, cell death analyzes, drug testing and wound healing, can be displayed in real time with depth information. For instance, in the L929 cell line, 24-hr imaging is required by using an incubator to observe cell separation with the given chemical process. The fact that the cell shape can not be perceived in 3D using AFM, which does not also give depth information and the necessity of labeling reveals the power of holographic technique.

In this course, demonstrations of understanding of holographic techniques, equipments, optics, applications on cell liens and cancer will be discussed. At the end of the course, participants will gain a broad insight into digital holographic technology. They will have broad information on the current literature about optics while they gain knowledge on important imaging techniques and their wide usages.

Keywords : Digital Holography, Cancer research, Depth information, Resolution

\section{IS-42}

BIOMEMS APPLICATIONS AND MICROFLUIDICS (FROM THE VIEWPOINT OF AN ENGINEER)

Yalın Kılıç

Solar Biyoteknoloji, Ltd. [SolarBiotec]

It has been long enough that almost no researcher who did not discuss a microfluidic or miniature system for a specific application remained. Although it has long been said and published, only a slight percentage of the proposed applications could make it to the market. While sketchy efforts for one-to-one miniaturization of conventional systems or misguided designs ignoring the final integration step and costs in scalability converted most of the Lab-on-a-Chips to indeed Chips-in-a-Lab, simple rational solutions recruiting simple structures already proved their success as commercial products. Since miniaturization is the new trend in diagnostic or bio-sensing applications, it is inevitable that electronic interfaces are also in need to shrink, as well as the microfluidic front-end devices. An engineer who aims to build a miniature solution for a bio-application is in need of miniature building blocks with proven performance. MEMS devices as sensors for droplet electrochemical cells found a widespread use in scientific literature and studies for developing a biosensor accelerated with increased availability of commercial electrodes chips. However, regardless of the size of the biosensor developed, most of them still depend on a computer controlled desktop instrument for performance. We have commercialized the market's smallest bi-potentiostat device as an electrochemical interface for biosensors, where complex voltammetric techniques, as well as amperometric ones could be performed. Indeed, an UART stand-alone thumb-tip size module for voltammetry and impedance spectroscopy is developed for wearable devices (Fig. 1).

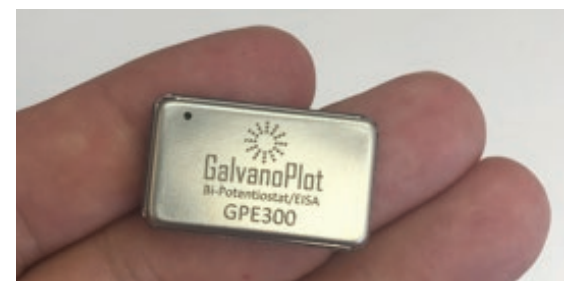

Figure 1. A stand-alone and compact electrochemical interface compatible with BioMEMSfor Point-of-Care devices or wearable diagnostics.

\section{IS-43}

\section{TRANSLATION TO CLINIC: LAB-ON-A-CHIP FOR REVEALING CANCER AND ADVANCING DRUG DISCOVERY}

Devrim Pesen Okvur

Izmir Institute of Technology, İzmir, Turkey

Classical cancer research and drug discovery use 2D cell culture coupled with animal testing for preclinical studies neither of which truly recapitulate the in vivo microenvironments in a human body. Using $3 \mathrm{D}$ cell culture in lab-on-achip (LOC) devices that can faithfully mimic the in vivo conditions, costs can be reduced ten-fold, results can be achieved ten times faster, animal testing can be significantly reduced and personalized medicine can be realized. Being the leading cause of cancer related deaths, it is essential to understand the complex metastasis phenomenon of cancer to develop new diagnostic and therapeutic strategies.

In this context, interactions of breast cancer cells with macrophages, a prominent duet of the tumor microenvironment was investigated using classical methods as well as custom LOC devices. Results showed that the EGF (epidermal growth factor) - CSF-1 (colony stimulating factor 1) loop is a paracrine - juxtacrine loop 
contrary to the generally accepted double paracrine loop.

In addition, invasion/chemotaxis of cancer cells into $3 \mathrm{D}$ matrigel was determined using LOC devices. Results showed that normal and cancer cells can be quantitatively differentiated based on their invasion/chemotaxis phenotypes as determined by confocal fluorescence microscopy imaging.

What's more, a LOC device and method was optimized to evaluate extravasation of normal and cancer cells. Results showed that normal and cancer cells can be quantitatively differentiated based on their extravasation phenotypes as determined by confocal fluorescence microscopy imaging.

Furthermore, using LOC devices, homing choices of breast cancer and liver cancer cells were determined. As expected, the former and the latter preferred lung and liver, respectively. Current work using patient derived circulating tumor cells suggests homing choices can be predicted using LOC devices comprising microenvironments mimicking target tissues.

Finally, a novel anti-cancer drug candidate was tested with 3D tri-culture in LOC devices comprising breast cancer cells, normal epithelial cells and macrophages. Results showed that the novel drug caused $60 \%$ less cell death in normal cells compared to the widely used drug doxorubicin in 3D tri-culture whereas both drugs had a similar effect on cell death in 3D mono-culture

Taken together these results demonstrate the importance of 3D cell culture in LOC devices for physiologically relevant results that can be translated to the clinic. Keywords: cancer, lab-on-a-chip, invasion, chemotaxis, metastasis.

\section{IS-44 \\ MICROFLUIDIC SYSTEMS FOR STEM CELL AND ORGANOID CULTURE}

Sinan Güven

Izmir Biomedicine and Genome Center, İzmir, Turkey

In vitro microphysiological platforms can host and maturate stem cell derived engineered human tissues. Such platforms provide novel research venues for life sciences by mimicking the native tissue architecture, biophysical environment and functionality. Advances in stem cell research enable the in vitro recapitulation of human organogenesis and let the generation of functional tissue models called organoids. Today, combination of on-chip microfluidic systems with stem cell technologies create many organ models such as lung, gut, brain, liver, kidney and stomach, which can be connected to form human-on-a-chip systems. Translation of these platforms to clinical settings promises effective disease models, test beds for toxicology and diagnosis. This talk covers fundamental aspects of on-chip system design and integration with stem cell research.

Keywords: induced pluripotent stem cell, organoid, microfluidic system, organon-a-chip, bioengineering

\section{ORAL PRESENTATION FULL TEXTS \& ABSTRACTS}

\author{
OP-01 \\ INVESTIGATION OF EPIDERMAL GROWTH FACTOR RECEPTOR \\ (EGFR) PATHWAY RELATED, EXOSOMAL MIRNAS IN NON-SMALL \\ CELL LUNG CANCER (NSCLC) CASES
}

$\underline{\text { Altug Koc }}^{1,2}$, Levent Pelit ${ }^{3}$, Asim Leblebici², Gizem Calibasi Kocal ${ }^{2}$, Haydar Soydane Karakus ${ }^{4}$, Ceyda Aldag ${ }^{4}$, Tuncay Goksel ${ }^{4}$, Yasemin Basbinar ${ }^{2}$ ${ }^{1}$ Department of Medical Genetics, Faculty of Medicine, Dokuz Eylul University Izmir, Turkey

${ }^{2}$ Department of Translational Oncology, Institute of Oncology, Dokuz Eylul University Izmir, Turkey

${ }^{3}$ Department of Chemistry, Faculty of Science, Ege University, Izmir, Turkey ${ }^{4}$ Department of Pulmonary Medicine, Faculty of Medicine, Ege University, Izmir, Turkey

OBJECTIVES: Recently, EGFR gene and its related pathways become an important issue for precision medicine practice in NSCLC cases. In the presence of activating somatic mutations of EGFR gene, which synthesize a thyrosine kinase, targeted use of "thyrosine kinase inhibitors" ameliorates the "progression free survival" rates. Exosomes are microvesicles that have content similar to tumor itself. DNA content of exosomes is used in the studies of somatic mutations Recent efforts revealed the possible association between EGFR pathways related miRNAs and the somatic mutations. In the presented study, exosomes are used for liquid biopsy approach.

MATERIALS AND METHODS: We wish to investigate, exosomal EGFR pathway related 4 miRNAs (miR-30b, miR-30c, miR-221-3p, miR-22-3p and miR-1288 as control) which are defined in literature previously and if possible their correlation with somatic mutations and clinical findings. Thirty-two samples from distinct NSCLC cases are analyzed. Exosomes are derived from peripheral blood plasma of the patients; miRNA extraction, cDNA synthesis, real-time quantitative PCR are done and $\Delta / \Delta \mathrm{Ct}$ method is used for relative quantification. RESULTS: The control miR1288 is expressed in all of the samples except one. Two of the miRNAs (miR-30b, miR-221-3p) produce weak PCR curves but because of inadequate amount of isolated miRNA, they are discarded from the study. The rest of the miRNAs (miR-30c, miR-22-3p) produced PCR curves.

CONCLUSIONS: The exosomal miR-30c, miR-22-3p are successfully derived from plasma of NSCLC cases and they seems to be potential biomarkers for these patients.

Keywords: EGFR, exosome, miRNA, Non-small Cell Lung Cancer (NSCLC)

\section{INTRODUCTION}

All over the world, the lung cancer is the leading one among cancer deaths. According to the World Health Organization data, about 2 million new lung cancer cases are diagnosed each year [1]. In our country, the incidence of lung cancer is 29,314 . More than $90 \%$ of these cases are males and their mean age is 60 years. About $47 \%$ of the cases are in advanced stage of disease at the time of diagnosis. Majority of them $(80,7 \%$ ) are Non-Small Cell Lung Cancer (NSCLC) [24531 patients $(63.0 \%$ ]. New treatment strategies targeting the tumor genotype enables the precision medicine. The major biomarkers for the NSCLC are the driver mutations of EGFR, ALK, MET, ROS1 and KRAS genes. Epidermal Growth Factor Receptor $(E G F R)$ gene mutations are seen in $15 \%$ of the NSCLC cases. The deletions of exon 19 and L858R mutation in EGFR gene increase the tyrosine kinase activity this gene. The drugs (erlotinib, gefitinib, afatinib) targeting these mutations are increases "progression free survival" [3]. The secondary EGFR mutations (T790M) are responsible for the acquired drug resistance in the $50 \%$ of the cases [4MET gene amplification is reported to occur in a subset of adenocarcinomas. Although somatic mutations of MET in lung adenocarcinomas are rare, all but one of those reported so far entail a splice mutation deleting the juxtamembrane domain for binding the c-Cbl E3-ligase; normally such binding leads to ubiquitination and receptor degradation, and loss of this domain leads to MET activation. The purpose of this study was to clarify in the role of MET activation in lung carcinogenesis. MATERIALS AND METHODS MET gene copy number was determined by real-time quantitative polymerase chain reaction in 187 of the patients with lung cancer and the MET gene splice mutation deleting the juxtamembrane domain was examined by direct sequencing in 262 . The results were correlated with various clinical and pathologic features including mutations of the epidermal growth factor receptor, KRAS, and HER2 genes. RESULTS All the instances of MET activation occurred in patients with adenocarcinomas. The 
contrary to the generally accepted double paracrine loop.

In addition, invasion/chemotaxis of cancer cells into $3 \mathrm{D}$ matrigel was determined using LOC devices. Results showed that normal and cancer cells can be quantitatively differentiated based on their invasion/chemotaxis phenotypes as determined by confocal fluorescence microscopy imaging.

What's more, a LOC device and method was optimized to evaluate extravasation of normal and cancer cells. Results showed that normal and cancer cells can be quantitatively differentiated based on their extravasation phenotypes as determined by confocal fluorescence microscopy imaging.

Furthermore, using LOC devices, homing choices of breast cancer and liver cancer cells were determined. As expected, the former and the latter preferred lung and liver, respectively. Current work using patient derived circulating tumor cells suggests homing choices can be predicted using LOC devices comprising microenvironments mimicking target tissues.

Finally, a novel anti-cancer drug candidate was tested with 3D tri-culture in LOC devices comprising breast cancer cells, normal epithelial cells and macrophages. Results showed that the novel drug caused $60 \%$ less cell death in normal cells compared to the widely used drug doxorubicin in 3D tri-culture whereas both drugs had a similar effect on cell death in 3D mono-culture

Taken together these results demonstrate the importance of 3D cell culture in LOC devices for physiologically relevant results that can be translated to the clinic. Keywords: cancer, lab-on-a-chip, invasion, chemotaxis, metastasis.

\section{IS-44 \\ MICROFLUIDIC SYSTEMS FOR STEM CELL AND ORGANOID CULTURE}

Sinan Güven

Izmir Biomedicine and Genome Center, İzmir, Turkey

In vitro microphysiological platforms can host and maturate stem cell derived engineered human tissues. Such platforms provide novel research venues for life sciences by mimicking the native tissue architecture, biophysical environment and functionality. Advances in stem cell research enable the in vitro recapitulation of human organogenesis and let the generation of functional tissue models called organoids. Today, combination of on-chip microfluidic systems with stem cell technologies create many organ models such as lung, gut, brain, liver, kidney and stomach, which can be connected to form human-on-a-chip systems. Translation of these platforms to clinical settings promises effective disease models, test beds for toxicology and diagnosis. This talk covers fundamental aspects of on-chip system design and integration with stem cell research.

Keywords: induced pluripotent stem cell, organoid, microfluidic system, organon-a-chip, bioengineering

\section{ORAL PRESENTATION FULL TEXTS \& ABSTRACTS}

\author{
OP-01 \\ INVESTIGATION OF EPIDERMAL GROWTH FACTOR RECEPTOR \\ (EGFR) PATHWAY RELATED, EXOSOMAL MIRNAS IN NON-SMALL \\ CELL LUNG CANCER (NSCLC) CASES
}

$\underline{\text { Altug Koc }}^{1,2}$, Levent Pelit ${ }^{3}$, Asim Leblebici², Gizem Calibasi Kocal ${ }^{2}$, Haydar Soydane Karakus ${ }^{4}$, Ceyda Aldag ${ }^{4}$, Tuncay Goksel ${ }^{4}$, Yasemin Basbinar ${ }^{2}$ ${ }^{1}$ Department of Medical Genetics, Faculty of Medicine, Dokuz Eylul University Izmir, Turkey

${ }^{2}$ Department of Translational Oncology, Institute of Oncology, Dokuz Eylul University Izmir, Turkey

${ }^{3}$ Department of Chemistry, Faculty of Science, Ege University, Izmir, Turkey ${ }^{4}$ Department of Pulmonary Medicine, Faculty of Medicine, Ege University, Izmir, Turkey

OBJECTIVES: Recently, EGFR gene and its related pathways become an important issue for precision medicine practice in NSCLC cases. In the presence of activating somatic mutations of EGFR gene, which synthesize a thyrosine kinase, targeted use of "thyrosine kinase inhibitors" ameliorates the "progression free survival" rates. Exosomes are microvesicles that have content similar to tumor itself. DNA content of exosomes is used in the studies of somatic mutations Recent efforts revealed the possible association between EGFR pathways related miRNAs and the somatic mutations. In the presented study, exosomes are used for liquid biopsy approach.

MATERIALS AND METHODS: We wish to investigate, exosomal EGFR pathway related 4 miRNAs (miR-30b, miR-30c, miR-221-3p, miR-22-3p and miR-1288 as control) which are defined in literature previously and if possible their correlation with somatic mutations and clinical findings. Thirty-two samples from distinct NSCLC cases are analyzed. Exosomes are derived from peripheral blood plasma of the patients; miRNA extraction, cDNA synthesis, real-time quantitative PCR are done and $\Delta / \Delta \mathrm{Ct}$ method is used for relative quantification. RESULTS: The control miR1288 is expressed in all of the samples except one. Two of the miRNAs (miR-30b, miR-221-3p) produce weak PCR curves but because of inadequate amount of isolated miRNA, they are discarded from the study. The rest of the miRNAs (miR-30c, miR-22-3p) produced PCR curves.

CONCLUSIONS: The exosomal miR-30c, miR-22-3p are successfully derived from plasma of NSCLC cases and they seems to be potential biomarkers for these patients.

Keywords: EGFR, exosome, miRNA, Non-small Cell Lung Cancer (NSCLC)

\section{INTRODUCTION}

All over the world, the lung cancer is the leading one among cancer deaths. According to the World Health Organization data, about 2 million new lung cancer cases are diagnosed each year [1]. In our country, the incidence of lung cancer is 29,314 . More than $90 \%$ of these cases are males and their mean age is 60 years. About $47 \%$ of the cases are in advanced stage of disease at the time of diagnosis. Majority of them $(80,7 \%$ ) are Non-Small Cell Lung Cancer (NSCLC) [24531 patients $(63.0 \%$ ]. New treatment strategies targeting the tumor genotype enables the precision medicine. The major biomarkers for the NSCLC are the driver mutations of EGFR, ALK, MET, ROS1 and KRAS genes. Epidermal Growth Factor Receptor $(E G F R)$ gene mutations are seen in $15 \%$ of the NSCLC cases. The deletions of exon 19 and L858R mutation in EGFR gene increase the tyrosine kinase activity this gene. The drugs (erlotinib, gefitinib, afatinib) targeting these mutations are increases "progression free survival" [3]. The secondary EGFR mutations (T790M) are responsible for the acquired drug resistance in the $50 \%$ of the cases [4MET gene amplification is reported to occur in a subset of adenocarcinomas. Although somatic mutations of MET in lung adenocarcinomas are rare, all but one of those reported so far entail a splice mutation deleting the juxtamembrane domain for binding the c-Cbl E3-ligase; normally such binding leads to ubiquitination and receptor degradation, and loss of this domain leads to MET activation. The purpose of this study was to clarify in the role of MET activation in lung carcinogenesis. MATERIALS AND METHODS MET gene copy number was determined by real-time quantitative polymerase chain reaction in 187 of the patients with lung cancer and the MET gene splice mutation deleting the juxtamembrane domain was examined by direct sequencing in 262 . The results were correlated with various clinical and pathologic features including mutations of the epidermal growth factor receptor, KRAS, and HER2 genes. RESULTS All the instances of MET activation occurred in patients with adenocarcinomas. The 